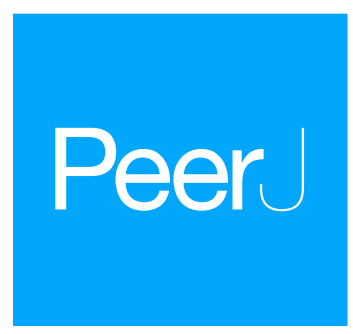

\title{
Quantitatively estimating main soil water-soluble salt ions content based on Visible-near infrared wavelength selected using GC, SR and VIP
}

\author{
Haifeng Wang ${ }^{1,2, *}$, Yinwen Chen ${ }^{3, *}$, Zhitao Zhang ${ }^{1,2}$, Haorui Chen ${ }^{4}$, \\ Xianwen $\mathrm{Li}^{2}$, Mingxiu Wang ${ }^{5}$ and Hongyang Chai ${ }^{2}$ \\ ${ }^{1}$ Key Laboratory of Agricultural Soil and Water Engineering in Arid and Semiarid Areas, Ministry of \\ Education, Northwest A\&F University, Yangling, Shaanxi, China \\ ${ }^{2}$ College of Water Resources and Architectural Engineering, Northwest A\&F University, Yangling, Shaanxi, \\ China \\ ${ }^{3}$ Department of Foreign Languages, Northwest A\&F University, Yangling, Shaanxi, China \\ ${ }^{4}$ Department of Irrigation and Drainage, China Institute of Water Resources and Hydropower Research, \\ Beijing, China \\ ${ }^{5}$ Department of Civil and Environmental Engineering, University of California, Irvine, CA, USA \\ These authors contributed equally to this work.
}

\section{ABSTRACT}

Soil salinization is the primary obstacle to the sustainable development of agriculture and eco-environment in arid regions. The accurate inversion of the major water-soluble salt ions in the soil using visible-near infrared (VIS-NIR) spectroscopy technique can enhance the effectiveness of saline soil management. However, the accuracy of spectral models of soil salt ions turns out to be affected by high dimensionality and noise information of spectral data. This study aims to improve the model accuracy by optimizing the spectral models based on the exploration of the sensitive spectral intervals of different salt ions. To this end, 120 soil samples were collected from Shahaoqu Irrigation Area in Inner Mongolia, China. After determining the raw reflectance spectrum and content of salt ions in the lab, the spectral data were pretreated by standard normal variable (SNV). Subsequently the sensitive spectral intervals

Submitted 23 October 2018 Accepted 19 December 2018 Published 22 January 2019

Corresponding author

Zhitao Zhang, zhitaozhang@126.com

Academic editor

Timothy Scheibe

Additional Information and Declarations can be found on page 20

DOI 10.7717/peerj.6310

Copyright

2019 Wang et al.

Distributed under

Creative Commons CC-BY 4.0 of each ion were selected using methods of gray correlation (GC), stepwise regression (SR) and variable importance in projection (VIP). Finally, the performance of both models of partial least squares regression (PLSR) and support vector regression (SVR) was investigated on the basis of the sensitive spectral intervals. The results indicated that the model accuracy based on the sensitive spectral intervals selected using different analytical methods turned out to be different: VIP was the highest, SR came next and GC was the lowest. The optimal inversion models of different ions were different. In general, both PLSR and SVR had achieved satisfactory model accuracy, but PLSR outperformed SVR in the forecasting effects. Great difference existed among the optimal inversion accuracy of different ions: the predicative accuracy of $\mathrm{Ca}^{2+}, \mathrm{Na}^{+}, \mathrm{Cl}^{-}, \mathrm{Mg}^{2+}$ and $\mathrm{SO}_{4}{ }^{2-}$ was very high, that of $\mathrm{CO}_{3}{ }^{2-}$ was high and $\mathrm{K}^{+}$was relatively lower, but $\mathrm{HCO}_{3}{ }^{-}$failed to have any predicative power. These findings provide a new approach for the optimization of the spectral model of water-soluble salt ions and improvement of its predicative precision. 
Subjects Soil Science, Data Mining and Machine Learning, Natural Resource Management, Environmental Impacts, Spatial and Geographic Information Science Keywords Soil salinization, Water-soluble salt ions, VIS-NIR, GC, SR, VIP, Model

\section{INTRODUCTION}

Soil salinization, one of the most important causes of land desertification and deterioration, has posed serious threat to agricultural development and sustainable utilization of natural resources (Shahid \& Rahman, 2011; Abbas et al., 2013). 950 million ha of soil worldwide has become salinized (Schofield \& Kirkby, 2003). Soil salinization is eroding and degenerating the arable soil at the speed of $10 \mathrm{ha} / \mathrm{min}$ (Graciela \& Alfred, 2009). Soil remediation and management are very difficult in China because of such complex natural factors as climate, terrain and geology, and human factors as unreasonable irrigation and disruption of ecological balance. The total area of saline soil in China is 36 million ha (Li et al., 2014), accounting for $4.88 \%$ of the total area available nationwide (The National Soil Survey Office, 1998). Saline soil usually has a high concentration of salt ions with a series of effects on the plants such as physiological draught, ion toxicity and metabolic disorder, thus forming "salt damage" (Munns, 2002; Tavakkoli et al., 2011). In addition, one major cause of the inaccuracy of soil salinity spectral measurement is that pure salts seldom exist in the soil because of some trace salt ion elements are always fixed in soil crystals. Therefore, quick and accurate acquisition of the detailed information of the various salt ions content in the soil can enhance the pertinence and effectiveness of saline soil management.

The traditional quantitative estimation of soil salt contents usually includes such steps as field soil sampling in fixed points, experiments in the laboratory and comprehensive statistical analysis (Urdanoz \& Aragüés, 2011). Such a method is incapable of the dynamic monitoring of saline soil in a large area because of its high consumption of time and energy, small number of measuring points and poor representativeness (Ding \& Yu, 2014). Compared with conventional laboratory analysis methods, remote sensing technology has been widely used due to its rich information, continuity, high precision and low cost (Ben-Dor, 2002; Viscarra Rossel et al., 2006; Viscarra Rossel \& Behrens, 2010; Viscarra Rossel $\&$ Webster, 2012). The various soil constituents (contents of water, salt, organic matter and so forth) can be acquired conveniently from remote sensing data (Gomez, Viscarra Rossel \& McBratney, 2008; Yu et al., 2010; Periasamy \& Shanmugam, 2017). Hence, with the abundant spectral reflection information within the VIS-NIR intervals of soil salinity, it is feasible to improve the accuracy of soil salinization inversion (Al-Khaier, 2003; Ben-Dor et al., 2009; Abbas et al., 2013).

The application of VIS-NIR spectral analysis technique has been proved effective in improving the accuracy of quantitative estimation and eliminating the external disturbance to some extent (Dehaan \& Taylor, 2002; Metternicht \& Zinck, 2003; Farifteh et al., 2008). The univariate linear regression on the basis of soil salinity index developed for CR (continuum removed) reflectance can be used as a method for soil salt content estimation (Weng, Gong \& Zhu, 2008). Due to the strong correlation between soil electrical conductivity (EC) and soil salinity, EC is also one of the important indicators for evaluating 
soil salinization degree. A variety of approaches have been used to acquire the EC in the field soil, including the partial least squares regression (PLSR) and multivariate adaptive regression splines (MARS) (Volkan Bilgili et al., 2010; Nawar, Buddenbaum \& Hill, 2015), logarithmic model (Xiao, Li ఓ Feng, 2016a), Bootstrap-BP neural network model (Wang et al., 2018d) and satellite remote sensing technology (Nawar et al., 2014; Bannari et al., 2018). In addition, the differential transformation (Xia et al., 2017) and fractional derivative (Wang et al., 2017; Wang et al., 2018c) can fully utilize the potential spectral information and enhance model accuracy. The methods of spectral classification (Jin et al., 2015) and water influence elimination (Chen et al., 2016; Peng et al., 2016b; Yang \& Yu, 2017) work well in improving the quantitative inversion accuracy of soil salinity. Therefore, the remote sensing technique is reliable to inverse the soil salinity quantitatively on different scales.

The quantitative analysis of VIS-NIR spectral intervals can help evaluate the content of some chemical elements (Viscarra Rossel et al., 2006; Farifteh et al., 2008; Cécillon et al., 2009; Ji et al., 2016) due to the different characteristic absorption spectrum in soil chemical elements. Besides, there exists a correlation between some principal salt ions $\left(\mathrm{Na}^{+}, \mathrm{Cl}^{-}\right)$ and spectral reflectance (Jiang et al., 2017). Therefore, VIS-NIR spectroscopy technique can be used to obtain the contents of the soil salt ions to a certain extent. The spectral response characteristics of mid-infrared (MIR) spectroscopy are better than those of VIS-NIR spectroscopy in predicting soil salinity information, the latter has high predicting accuracy of the total salts content, $\mathrm{HCO}_{3}{ }^{-}, \mathrm{SO}_{4}{ }^{2-}$ and $\mathrm{Ca}^{2+}$, followed by $\mathrm{Mg}^{2+}, \mathrm{Cl}^{-}$and $\mathrm{Na}^{+}$ (Peng et al., 2016a). The spectral models have satisfactory prediction of the SAR (sodium absorption ratio) of soil salinization evaluation parameter, which is composed of the contents of $\mathrm{Ca}^{2+}, \mathrm{Mg}^{2+}$ and $\mathrm{Na}^{+}$(Xiao, Li \& Feng, 2016b). Qu et al. (2009) found that the contents of the total salt, $\mathrm{SO}_{4}{ }^{2-}, \mathrm{pH}$ and $\mathrm{K}^{+}+\mathrm{Na}^{+}$have a higher inversion accuracy using spectral data to create PLSR model. The different pretreatment of the different ion models varies by creating and analyzing PLSR model that demonstrates relatively good predictive effects like ion contents of $\mathrm{Ca}^{2+}, \mathrm{Mg}^{2+}, \mathrm{SO}_{4}{ }^{2-}, \mathrm{Cl}^{-}$, and $\mathrm{HCO}_{3}{ }^{-}$(Dai et al., 2015). Overall, PLSR is a frequently used and robust linear model for quantitative research because it has inference capabilities which are useful to model a probable linear relationship between the reflectance spectra and the salt ions content in soil. However, the non-uniform data and non-linear reflectance in spectral information of some soil chemical elements lead to the reduction in model accuracy (Viscarra Rossel \& Behrens, 2010; Nawar, Buddenbaum \& Hill, 2015). In particular, support vector regressions (SVR) based on kernel-based learning methods has the ability to handle nonlinear analysis case with high model accuracy (Vapnik, 1995; Peng et al., 2016a; Hong et al., 2018b). Over the past several decades, the use of SVR for classification and regression has been extensively applied in soil VIS-NIR spectroscopy (Ben-Dor, 2002; Xiao, Li \& Feng, 2016b; Hong et al., 2018a). Moreover, the SVR model works well in estimating the contents of $\mathrm{K}^{+}, \mathrm{Na}^{+}, \mathrm{Ca}^{2+}$ and $\mathrm{SO}_{4}{ }^{2-}$ in the soil (Wang et al., 2018a). Thus, the correct way of modeling helps to guarantee the model accuracy (Farifteh et al., 2007).

Many researches focused on the inversion of soil salinity using spectral information. Nevertheless, little research has explored the eight water-soluble salt ions $\left(\mathrm{K}^{+}, \mathrm{Ca}^{2+}\right.$, $\mathrm{Na}^{+}, \mathrm{Mg}^{2+}, \mathrm{Cl}^{-}, \mathrm{SO}_{4}{ }^{2-}, \mathrm{HCO}_{3}{ }^{-}$and $\left.\mathrm{CO}_{3}{ }^{2-}\right)$ using spectral information in the soil. The 
model fitting of ions and spectral information still needs improving (Farifteh et al., 2008; Peng et al., 2016a). Apart from the suitable multivariate statistical analysis method that can partly improve the inversion effects, reduction of redundant information is another identified approach to further optimize the model (Bannari et al., 2018; Stenberg et al., 2010). Plenty of studies have demonstrated that spectral variable selection methods can not only reduce the complexity of calibration models, but also improve the model predictive performance (Hong et al., 2018a). To select the optimal spectral variable subset, scholars have investigated varied methods such as gray correlation (GC) (Li et al., 2016; Wang et al., 2018b), stepwise regression (SR) (Zhang et al., 2018) and variable importance in projection (VIP) (Qi et al., 2017), and have achieved satisfactory effects. In addition, all the three methods have been widely applied in many studies, such as plant physiology, food engineering, mathematical statistics (Oussama et al., 2012; Maimaitiyiming et al., 2017; Liu, Yang \& Wu, 2015). However, few studies have concentrated on the use of variable selection algorithms in the inversion of soil salt ions.

This study aims to: (1) build the optimal model of soil salt ions using VIS-NIR spectroscopy technique; (2) compare the models based on the sensitive spectral ranges selected using GC, SR and VIP methods for different soil ions; (3) compare the performance of PLSR and SVR models, and identify the optimal models for different ions.

\section{MATERIALS AND METHODS}

\section{Study area}

Hetao Irrigation District (HID), with Yin Mountains at its north, the Yellow River at its south, Ulanbuh Desert at its west and Baotou at its east, lies in Bayannur League, Inner Mongolia, China. It consists of irrigation areas of Ulan Buh, Jiefangzha, Yongji, Yichang and Urat, and it is China's largest irrigation district with a total size of $5740 \mathrm{~km}^{2}$ (Yu et al., 2010). In addition, HID is an important production base of cereal and oil plants in China with major crops of wheat, corn and sunflower. Shahaoqu Irrigation Area (SIA), a typical region of saline soil in HID, was chosen as the study area. SIA $\left(107^{\circ} 05^{\prime} \sim 107^{\circ} 10^{\prime} \mathrm{E}\right.$, $40^{\circ} 52^{\prime} \sim 41^{\circ} 00^{\prime} \mathrm{N}$ ) is located in the central east of Jiefangzha Irrigation Area. SIA belongs to typical continental climate, having hot summers, chilly winters, rare precipitation and strong evaporation. Its mean annual temperature, precipitation, potential evaporation is about $7.1^{\circ} \mathrm{C}, 155 \mathrm{~mm}$ and 2,000 $\mathrm{mm}$, respectively. Physiographically, the mean elevation and slope of SIA are about $1,030 \mathrm{~m}$ and 1/10,000, respectively. According to the World Reference Base for Soil Resources (WRB), the local soil texture is mainly silty clay loam with varying degrees of saline soil. Over the years, due to its gentle terrain slope, poor groundwater runoff, intense land surface evaporation and irrational farming activities, about $60 \%$ of the land within the district has been affected by various degree of salinization, which seriously restricted the agricultural development (Wu et al., 2008; Gao et al., 2015).

\section{Sample collection and chemical analysis}

The Hetao irrigation district administration gave field permit approval to us (NO. 2017YFC0403302). To ensure the representativeness of soil samples, the samples were randomly gathered from a total of 120 sampling units on a grid of $16 \mathrm{~m} \times 16 \mathrm{~m}$ (because 


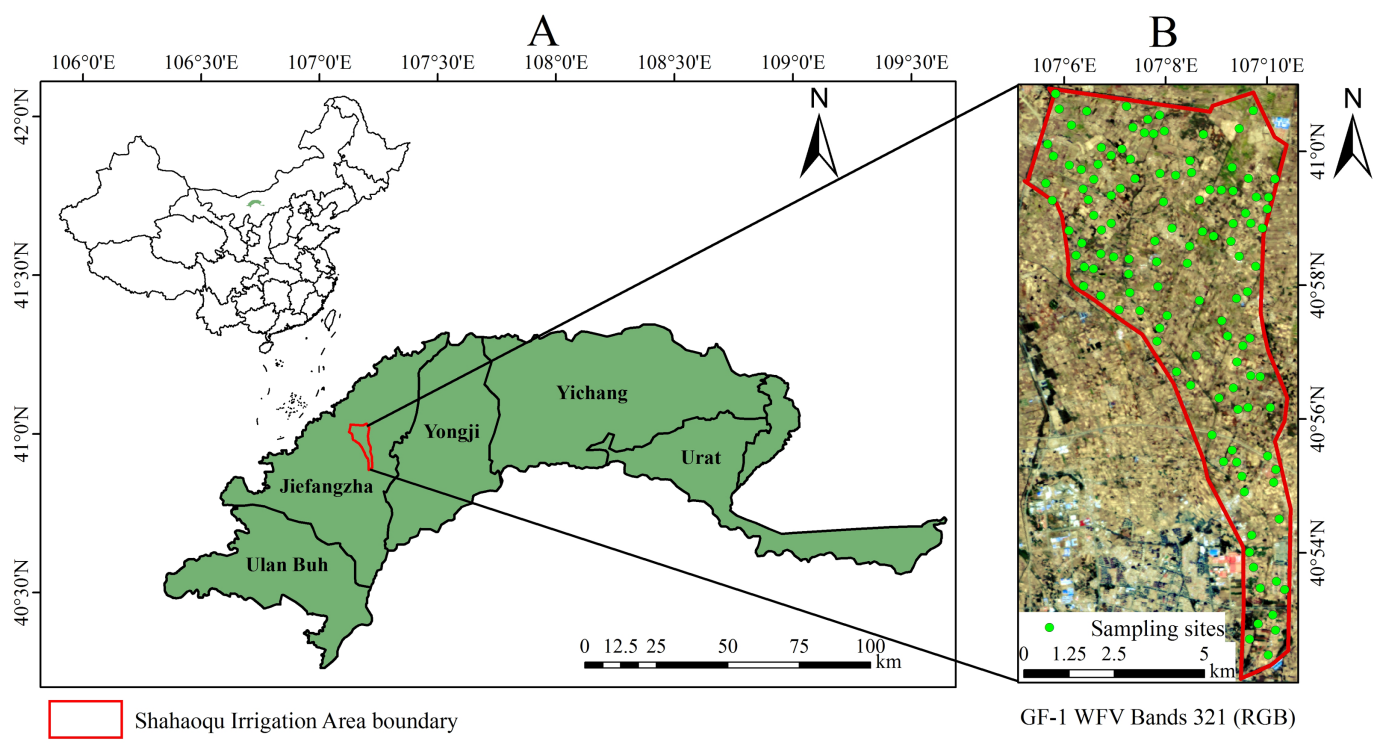

Figure 1 Distribution of sampling sites in the study area. (A) Location map of Shahaoqu Irrigation Area. (B) Sampling location in Shahaoqu Irrigation Area.

Full-size DOI: 10.7717/peerj.6310/fig-1

the spatial resolution of GF-1 satellite imagery is $16 \mathrm{~m}$ ) in the study area during October 12 22, 2017 (Fig. 1). In each unit, approximately $0.5 \mathrm{~kg}$ of topsoil $(0-5 \mathrm{~cm})$ was collected at four randomly selected sampling sites and then mixed thoroughly to obtain a representative sample. Overall, a total of 120 soil samples were acquired, and each sample was stored in a plastic bag, labeled and sealed. A portable global position system (GPS) was used to determine the coordinates of sampling points. Subsequently, the soil samples were transported to the lab to receive a series of such treatments as sufficient natural air-drying for two weeks and rubbing through a $2 \mathrm{~mm}$ sieve to exclude small stones and other impurities. Each sample was divided into two subsamples to be used for spectra collection and physiochemical analysis.

Each $50 \mathrm{~g}$ of soil sample was put into a respective flask, and $250 \mathrm{ml}$ of distilled water (the ratio of water to soil is 5:1) were added into each flask. The water-soluble ion contents were measured in the filtrate obtained from full soaking, oscillation and filtration (Aboukila \& Norton, 2017). $\mathrm{Ca}^{2+}$ and $\mathrm{Mg}^{2+}$ were measured using EDTA titration, $\mathrm{Na}^{+}$and $\mathrm{K}^{+}$flame photometry, $\mathrm{CO}_{3}{ }^{2-}$ and $\mathrm{HCO}_{3}{ }^{-}$double indicator-neutralization titration, $\mathrm{Cl}^{-}$silver nitrate titration, and $\mathrm{SO}_{4}{ }^{2-}$ EDTA indirect complexometry $(\mathrm{Bao}, 2000)$. The content of $\mathrm{CO}_{3}{ }^{2-}$ was too low (approximately 0 ) in some soil samples because $\mathrm{CO}_{3}{ }^{2-}$ is liable to integrate with $\mathrm{Ca}^{2+}$ and $\mathrm{Mg}^{2+}$ as sediment in a weak alkaline solution (Table 1). Coefficient of variation $(\mathrm{CV})$ reflects the degree of discreteness, and a positive correlation exists in two variables. The high CV helps to build a robust model (Dai et al., 2015). The grading of CV showed a wide range of variation among different ions, among which the ion contents of $\mathrm{K}^{+}, \mathrm{Na}^{+}$and $\mathrm{SO}_{4}{ }^{2-}$ are over $100 \%$, showing a strong variability, and those of $\mathrm{CO}_{3}{ }^{2-}, \mathrm{Cl}^{-}$, $\mathrm{Ca}^{2+}, \mathrm{Mg}^{2+}$ and $\mathrm{HCO}_{3}{ }^{-}$are between $10 \%$ and $100 \%$, having a moderate variability. 


\begin{tabular}{llllll}
\hline $\begin{array}{l}\text { Table } 1 \\
\text { Statistical } \\
\text { index }\end{array}$ & $\begin{array}{l}\text { Descriptive statistics of soil water-soluble salt ions content. } \\
\mathbf{g ~ k g}\end{array}$ & $\begin{array}{l}\text { Maximum/ } \\
\mathbf{g ~ k g}\end{array}$ & $\begin{array}{l}\text { Mean/ } \\
\mathbf{g ~ k g}\end{array}$ & $\begin{array}{l}\text { Standard } \\
\text { deviation }\end{array}$ & $\begin{array}{l}\text { Coefficient } \\
\text { of variation/\% }\end{array}$ \\
\hline $\mathrm{CO}_{3}{ }^{2-}$ & 0.000 & 0.066 & 0.020 & 0.020 & 98.86 \\
$\mathrm{HCO}_{3}^{-}$ & 0.171 & 0.666 & 0.316 & 0.099 & 31.27 \\
$\mathrm{SO}_{4}{ }^{2-}$ & 0.047 & 40.892 & 9.073 & 10.828 & 119.34 \\
$\mathrm{Cl}^{-}$ & 0.145 & 23.234 & 4.825 & 4.711 & 97.65 \\
$\mathrm{Ca}^{2+}$ & 0.080 & 4.111 & 0.697 & 0.669 & 95.95 \\
$\mathrm{Mg}^{2+}$ & 0.039 & 1.952 & 0.706 & 0.606 & 85.91 \\
$\mathrm{~K}^{+}$ & 0.001 & 5.727 & 0.936 & 1.358 & 145.14 \\
$\mathrm{Na}^{+}$ & 0.016 & 23.035 & 5.014 & 5.563 & 110.94 \\
\hline
\end{tabular}

\section{Laboratory spectral measurements and pretreatments}

The soil samples were put into black vessels with a diameter of $10 \mathrm{~cm}$ and depth of $2 \mathrm{~cm}$ for spectral data collection and the surfaces were smoothed with a straightedge in the laboratory. The spectral data of the soil samples were measured using ASD (Analytical Spectral Devices, Inc., Boulder, CO, USA) FieldSpec ${ }^{\circledR} 3$ spectrometer with spectral range from 350-2,500 $\mathrm{nm}$. This instrument is equipped with two sensors whose spectral resolutions are $1.4 \mathrm{~nm}$ and $2 \mathrm{~nm}$, for the region of 350-1,000 $\mathrm{nm}$ and 1,000-2,500 nm, respectively. The spectral data was measured in a dark room with the light sources which have halogen lamps of 50 $\mathrm{W}, 50 \mathrm{~cm}$ from the sample soil surfaces, and $30^{\circ}$ incident angle to reduce the effects of external factors to the minimum. The field angle of fiber-optics probe is $5^{\circ}$, and it is $15 \mathrm{~cm}$ from the sample soil surface. The light source and spectrometer had been fully preheated, and the spectrometer had been corrected with a standardized white panel (99\% reflectance) prior to each measurement to reduce measurement error. Each sample soil was measured in four directions ( 3 turns, each is $90^{\circ}$ ), the spectrum was collected five times in each direction, and altogether there were 20 curves of the spectrum (Hong et al., 2018b). These curves were used as the raw spectral reflectance $\left(R_{\text {raw }}\right)$ after having the arithmetic mean in ViewSpecPro software version 6.0. The gaps of the spectral curves near 1,000 $\mathrm{nm}$ and 1,800 $\mathrm{nm}$ were corrected using the Splice Correction function (Xiao, Li \& Feng, 2016a).

The fluctuation would affect the accuracy of subsequent modeling because of such disturbance as the external environment, instrument noise and random error in spectral data collection. In general, a series of effective pretreatment, including smoothing, resampling and transformation etc., can eliminate the external noise to some degree, and then enhance the spectral characteristics (Ding et al., 2018). Therefore, it is necessary to pretreat $R_{\text {raw }}$ in the following steps. (i) The marginal wavelength (350-399 nm and 2,401-2,500 nm) of higher noise in each soil sample was removed, then remaining spectrum data was smoothed with filter method (window size is 5 and polynomial order is 2) using Savitzky-Golay (SG) (Savitzky \& Golay, 1964) via Origin Pro software version 2017SR2. (ii) The spectral data between 400 and 2,400 $\mathrm{nm}$ was resampled with a $10 \mathrm{~nm}$ of sample interval to keep the spectral features and remove redundant information (Xu et al., 2016). A new spectral curve consisting of 200 wave bands was obtained. (iii) The precise $R_{\text {raw-SNV }}$ was obtained by using the standard normal variable (SNV) to eliminate the effects of soil 

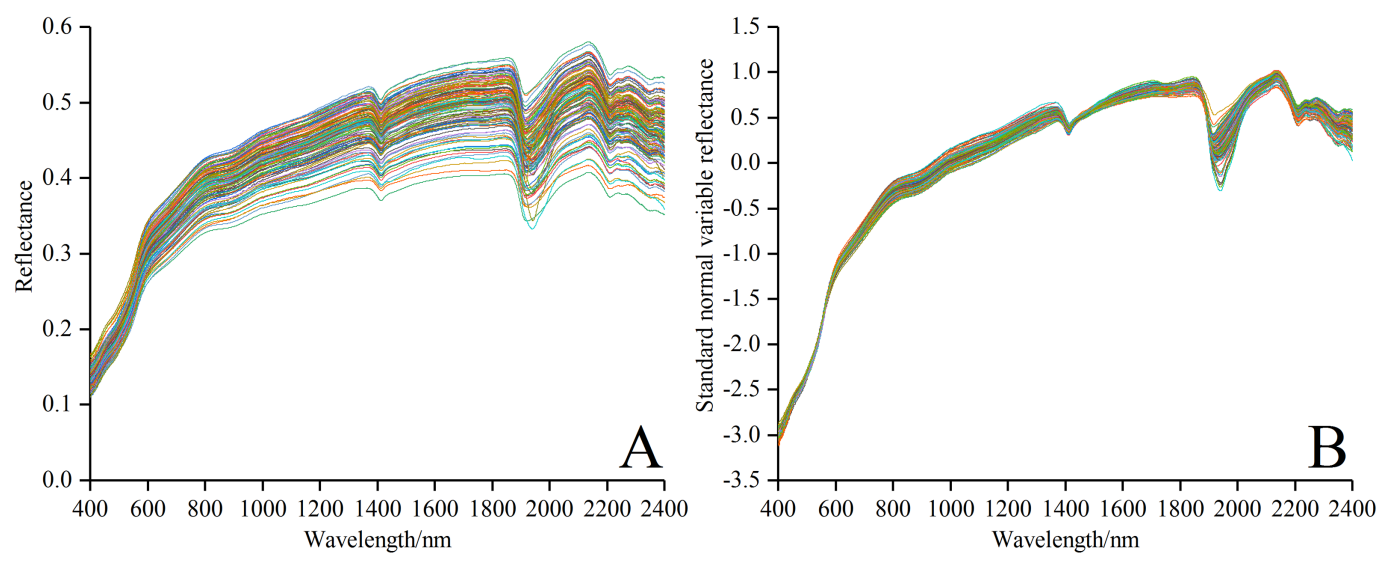

Figure 2 Spectral curves of all soil samples. (A) Reflectance spectral curves. (B) Standard normal variable reflectance curves.

Full-size DOI: 10.7717/peerj.6310/fig-2

particle size, surface scattering and baseline shift on the spectrum data (Xiao, Li \& Feng, 2016b; Barnes, Dhanoa \& Lister, 1989). The spectral curves of $R_{\text {raw }}$ and $R_{\text {raw-SNV }}$ are shown in Figs. 2A and 2B. Notably, comparison indicated that the spectral curve in Fig. 2B was much smoother than that in Fig. 2A, which made for the subsequent modeling.

\section{Gray correlation (GC)}

The GC, as one grey system theory, seeks the primary and secondary relations and analyzes the different effects of all the factors in a system (Deng, 1982; Li et al., 2016). Its calculation process is as follows: the reference sequence is $X_{0}=\left\{x_{0}(t), t=1,2, \ldots, n\right\}$, the comparative sequence is $X_{i}=\left\{x_{i}(t), t=1,2, \ldots, n\right\}$, and the formula of the gray correlation degree (GCD) between $X_{0}$ and $X_{i}$ is

$\mathrm{GCD}=\frac{1}{n} \sum_{t=1}^{n} \gamma\left(x_{0}(t), x_{i}(t)\right)$

where $\gamma\left(x_{0}(t), x_{i}(t)\right)=\frac{\min _{i} \min _{t}\left|x_{0}(t)-x_{i}(t)\right|+\rho \max _{i} \max _{t}\left|x_{0}(t)-x_{i}(t)\right|}{\left|x_{0}(t)-x_{i}(t)\right|+\rho \max _{i} \max _{t}\left|x_{0}(t)-x_{i}(t)\right|}$

$\rho$ is the distinguishing coefficient within $[0,1] . \rho$ was set as 0.1 in this paper.

The inconsistent dimension between the spectral data and the contents of different ions has some effects on the data analysis. Therefore, normalizing the spectral data preprocessing method can reduce these disadvantageous effects (Liu, Yang \& Wu, 2015; Wang et al., 2018b). In this paper, the larger the GCD of a certain band is, the closer relation the band and the ion content has, and vice versa.

\section{Variable importance in projection (VIP)}

The VIP is a variable selection method based on PLSR (Oussama et al., 2012). The explanatory power of the independent variables to the dependent variables is achieved by calculating the VIP score. The independent variables are sequenced according to the 
explanatory power (Qi et al., 2017). The VIP score for the $j$-th variable is given as:

$\mathrm{VIP}_{j}=\sqrt{\frac{p * \sum_{f=1}^{F} \mathrm{SSY}_{f} * \mathrm{~W}_{j f}^{2}}{\mathrm{SSY}_{\text {total }} * F}}$

Where $p$ is the number of independent variables; $f$ is the total number of components; $\mathrm{SSY}_{f}$ is the sum of squares of explained variance for the $f$-th component and $p$ the number of independent variables. SSY total is the total sum of squares explained of the dependent variable. $\mathrm{W}_{j f}^{2}$ gives the importance of the $j$-th variable in each $f$-th component. The higher value $\mathrm{VIP}_{j}$ has, the stronger explanatory power the independent variable has over the dependent variable. The VIP scores of independent variables have been recognized as a useful measure to identify important wavelengths when the score is more than 1 (Wold, Sjöström \& Eriksson, 2001; Maimaitiyiming et al., 2017).

\section{Model construction and validation}

Two-thirds of the samples were used for modeling $(n=80)$ and one third for validation ( $n=40)$ using Kennard-Stone (K-S) to calculate the Euclidean distance among different samples to ensure the statistical characteristics of modeling and the validation datasets resembled that of the whole sample set (Kennard \& Stone, 1969).

The PLSR and SVR models were applied to the quantitative inversion of different water-soluble salt ion contents in the saline soil in this paper. The PLSR model is a new stoichiometric statistical model. Compared with the traditional multivariate least squares regression (MLSR), PLSR can overcome the multicollinearity among the variables, reduce the dimension, synthesize and filter the information, extract the aggregate variables with the strongest explanatory power in the system, and exclude the noise with no explanatory power (Wold, Sjöström \& Eriksson, 2001). The optimal fitting model was built using the number of optimal principal components through full cross validation. SVR model is a new machine learning method based on the principle of structural risk minimization provided by the statistical learning theory. This model is characterized by its ability of solving such problems as limited sample size, nonlinear data processing and spatial pattern recognition of high-dimension data (Vapnik, 1995). During the modeling in this study, the type of SVR and kernel were set as epsilon-SVR and linear function, respectively; the penalty parameter $C$ and nuclear parameter $g$ were acquired by a grid-searching technique and a leave-one-out cross validation procedure. The optimal values of $C$ and $g$ were selected when the minimum $\mathrm{RMSE}_{\mathrm{CV}}$ (root mean squared error of cross validation) was produced (Xiao, Li \& Feng, 2016b). The two models were constructed and validated using the Unscrambler software version X10.4 (CAMO AS Oslo, Oslo, Norway).

Precision indices of determination coefficient of calibration $\left(R_{c}^{2}\right)$, determination coefficient of prediction $\left(R_{p}{ }^{2}\right)$, root mean squared error (RMSE) and ratio of performance to deviation (RPD) were used to evaluate the performance of these models. RPD classification was adopted to facilitate the interpretation of predictive results: a model is considered as excellent when RPD $\geq 2.5$, as very good when $2.0 \leq \mathrm{RPD}<2.5$, as good when $1.8 \leq \mathrm{RPD}$ $<2.0$, and as satisfactory when $1.4 \leq \mathrm{RPD}<1.8$ and can only distinguish between high and low values when $1.0 \leq$ RPD $<1.4$ (Viscarra Rossel, Taylor \& McBratney, 2007). Generally, 


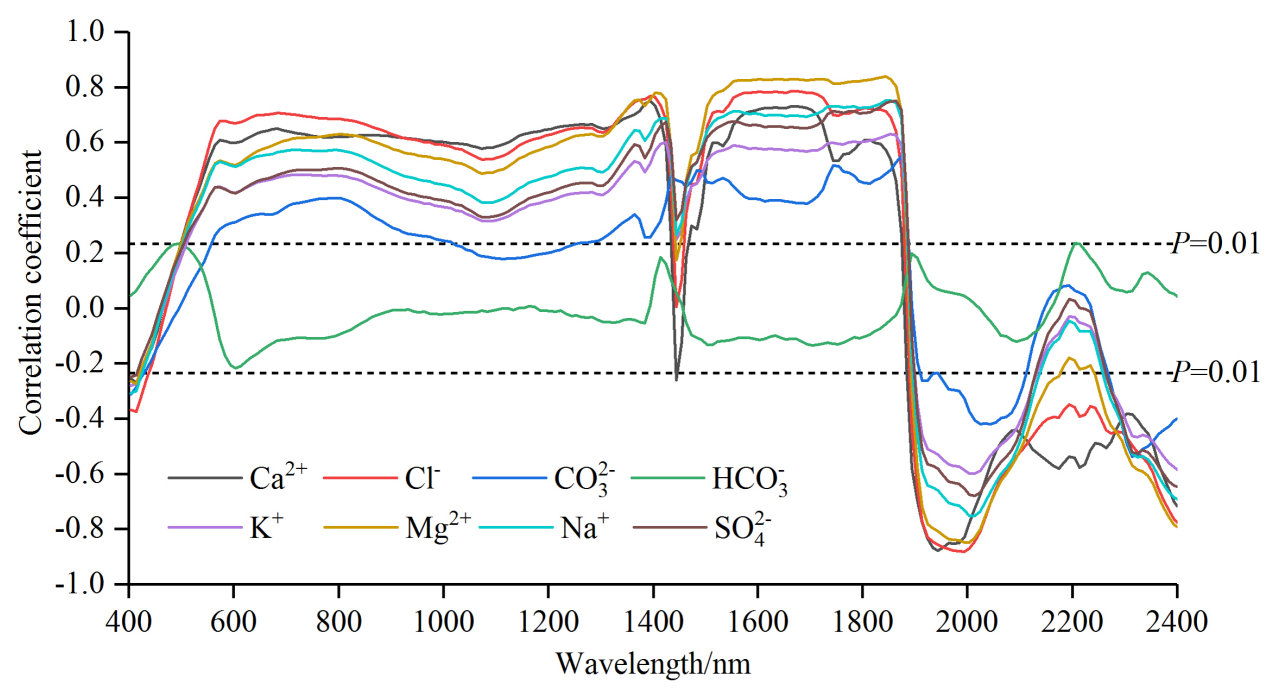

Figure 3 Correlation coefficients of soil water-soluble salt ions content with standard normal variable reflectance.

Full-size DOI: 10.7717/peerj.6310/fig-3

Table 2 Max correlation coefficient and band intervals of soil water-soluble salt ions content with standard normal variable reflectance.

\begin{tabular}{llll}
$\begin{array}{l}\text { Water-soluble } \\
\text { salt ions }\end{array}$ & $\begin{array}{l}\text { Number of } \\
\text { significant bands }\end{array}$ & $\begin{array}{l}\text { Maximum correlation } \\
\text { coefficient }\end{array}$ & $\begin{array}{l}\text { Maximum correlation } \\
\text { band intervals/nm }\end{array}$ \\
\hline $\mathrm{Ca}^{2+}$ & 190 & -0.877 & $1,940 \sim 1,950$ \\
$\mathrm{Cl}^{-}$ & 192 & -0.882 & $1,990 \sim 2,000$ \\
$\mathrm{CO}_{3}{ }^{2-}$ & 146 & 0.552 & $1,870 \sim 1,880$ \\
$\mathrm{HCO}_{3}{ }^{-}$ & 1 & 0.235 & $2,200 \sim 2,210$ \\
$\mathrm{~K}^{+}$ & 178 & 0.630 & $1,850 \sim 1,860$ \\
$\mathrm{Mg}^{2+}$ & 186 & -0.848 & $1,990 \sim 2,000$ \\
$\mathrm{Na}^{+}$ & 181 & -0.752 & $2,010 \sim 2,020$ \\
$\mathrm{SO}_{4}{ }^{2-}$ & 178 & 0.749 & $1,860 \sim 1,870$ \\
\hline
\end{tabular}

the most robust model would be the one with the largest $R_{c}{ }^{2}, R_{p}{ }^{2}$ (approach to 1) and RPD value and the lowest RMSE value.

\section{RESULTS}

\section{Correlation between water-soluble salt ions content and spectral reflectance}

The correlation coefficients (Pearson correlation) between each soil salt ion content and $R_{\text {raw-SNV }}$ in the range of 400-2,400 nm were tested with the significance level of $P<0.01$ $(|r|=0.234$ or above). The curves of correlation coefficients of soil salt ions were plotted in Fig. 3 and the numbers of bands passing the significance test were counted in Table 2. The curve patterns of $\mathrm{SO}_{4}{ }^{2-}, \mathrm{Cl}^{-}, \mathrm{Ca}^{2+}, \mathrm{Mg}^{2+}, \mathrm{K}^{+}$and $\mathrm{Na}^{+}$were similar (Fig. 3). From $400 \mathrm{~nm}$ to about $550 \mathrm{~nm}$, the correlation coefficients rose sharply from negative to positive, moved with a gentle depression until $1,400 \mathrm{~nm}$, plummeted and surged up to $1,560 \mathrm{~nm}$ 


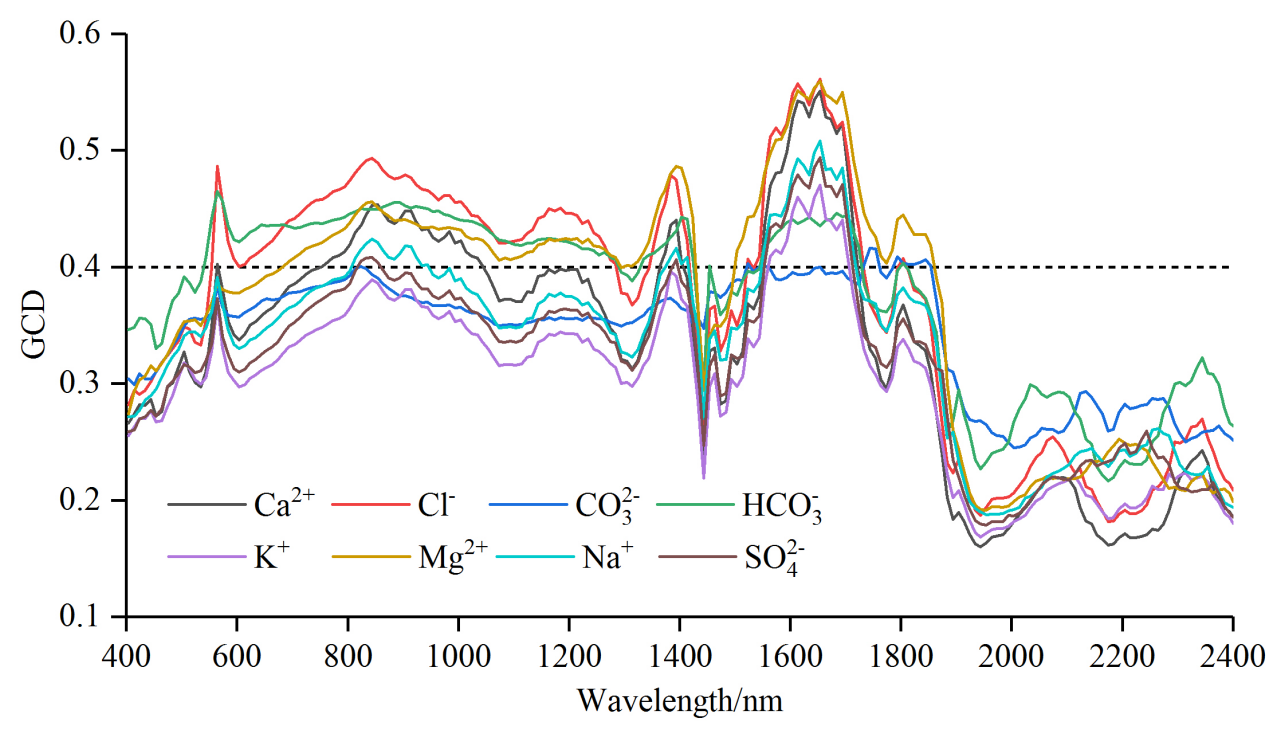

Figure 4 Gray correlation degree (GCD) for soil water-soluble salt ions content with standard normal variable reflectance.

Full-size DOI: 10.7717/peerj.6310/fig-4

(among the curves, the change of $\mathrm{Ca}^{2+}$ was the sharpest), and maintained a relative stable state to $1850 \mathrm{~nm}$. And then from 1,850 to 2,400 nm, dramatic oscillating variations alternated between rise and fall. In the intervals of $400-1,400 \mathrm{~nm}$ and 1,850-2,400 $\mathrm{nm}$ the curve pattern of $\mathrm{CO}_{3}{ }^{2-}$ was similar to that of other ions such as $\mathrm{SO}_{4}{ }^{2-}$. But between 1,400 $\mathrm{nm}$ and about $1,850 \mathrm{~nm}$, the curve took on a unique pattern: sustained oscillating rise. The coefficient curve of $\mathrm{HCO}_{3}^{-}$displayed a smaller variation, smoothly fluctuating between -0.2 and 0.2 . The complex variation of the coefficient curves of different ions revealed rich spectral information.

\section{Selection of characteristic wavelength Characteristic wavelength selection based on GC method}

The curves of gray correlation degree for soil water-soluble salt ions content and $R_{\text {raw-SNV }}$ were shown in Fig. 4. The correlation coefficient curves of the seven ions except $\mathrm{CO}_{3}{ }^{2-}$ resembled those of the GCD of the $R_{\text {raw-SNV }}$. Generally, the curves exhibited patterns of "oscillatory rise, fluctuation, rapid rise and fall, and oscillatory fluctuation". The gray correlation curves of $\mathrm{CO}_{3}{ }^{2-}$ followed a pattern of "ascending, plummeting, and smooth transition". The analysis of the GC curve amplitude showed the amplitudes of $\mathrm{Cl}^{-}, \mathrm{Mg}^{2+}$ and $\mathrm{Ca}^{2+}$ were relatively large, and those of $\mathrm{Na}^{+}, \mathrm{SO}_{4}{ }^{2-}, \mathrm{K}^{+}$and $\mathrm{HCO}_{3}{ }^{-}$were relatively small, and that of $\mathrm{CO}_{3}{ }^{2-}$ was relatively gentle.

The order of the maximal GCD was: $\mathrm{Cl}^{-}(0.561)>\mathrm{Mg}^{2+}(0.559)>\mathrm{Ca}^{2+}(0.551)>\mathrm{Na}^{+}$ $(0.508)>\mathrm{SO}_{4}{ }^{2-}(0.494)>\mathrm{K}^{+}(0.470)>\mathrm{HCO}_{3}{ }^{-}(0.465)>\mathrm{CO}_{3}{ }^{2-}(0.416)$. To ensure that each salt ion had sensitive bands as far as possible, the GCD threshold value was set as 0.40 to select the wavelength. The sensitive band was counted through gray correlation method (Table 3). The numbers of sensitive bands of different ions could be sequenced from the largest to the smallest as follows: $\mathrm{Mg}^{2+}(110)>\mathrm{HCO}_{3}^{-}(105)>\mathrm{Cl}^{-}(101)>\mathrm{Ca}^{2+}(53)>$ 


\begin{tabular}{|c|c|c|c|}
\hline $\begin{array}{l}\text { Water-soluble } \\
\text { salt ions }\end{array}$ & $\begin{array}{l}\text { Sensitive band } \\
\text { numbers }\end{array}$ & $\begin{array}{l}\text { Maximum gray } \\
\text { correlation degree }\end{array}$ & $\begin{array}{l}\text { Maximum gray } \\
\text { correlation } \\
\text { degree intervals/nm }\end{array}$ \\
\hline $\mathrm{Ca}^{2+}$ & 53 & 0.551 & $1,650 \sim 1,660$ \\
\hline $\mathrm{Cl}^{-}$ & 101 & 0.561 & $1,650 \sim 1,660$ \\
\hline $\mathrm{CO}_{3}{ }^{2-}$ & 14 & 0.416 & $1,740 \sim 1,750$ \\
\hline $\mathrm{HCO}_{3}^{-}$ & 105 & 0.465 & $560 \sim 570$ \\
\hline $\mathrm{K}^{+}$ & 15 & 0.470 & $1,650 \sim 1,660$ \\
\hline $\mathrm{Mg}^{2+}$ & 110 & 0.559 & $1,650 \sim 1,660$ \\
\hline $\mathrm{Na}^{+}$ & 36 & 0.508 & $1,650 \sim 1,660$ \\
\hline $\mathrm{SO}_{4}^{2-}$ & 21 & 0.494 & $1,650 \sim 1,660$ \\
\hline
\end{tabular}

$\mathrm{Na}^{+}(36)>\mathrm{SO}_{4}{ }^{2-}(21)>\mathrm{K}^{+}(15)>\mathrm{CO}_{3}{ }^{2-}(14)$. Therefore, the orders of sensitive band numbers and maximal GCD values had great difference. Furthermore, the band intervals corresponding to the maximum GCD of different salt ions were as follows: $\mathrm{CO}_{3}{ }^{2-}$ was near-infrared between 1,740 and $1,750 \mathrm{~nm}, \mathrm{HCO}_{3}{ }^{-}$was green light between 560 and 570 $\mathrm{nm}$, and the rest of six ions were near-infrared between 1,650 and 1,660 $\mathrm{nm}$.

\section{Characteristic wavelength selection based on SR method}

Feature band intervals were selected by stepwise regression method in SPSS software version 23.0 (IBM, Chicago, IL, USA), and the significance levels of variables acceptance and rejection were set at 0.10 and 0.15 (Zhang et al., 2018). The parameter indexes of feature band intervals selection were shown in Table 4 by stepwise regression method at maximum adjusted $R^{2}$.

Great difference existed among the optimal SR models of different ions, and the numbers of band intervals accepted by the model range from 3 to 8 (Table 4). The SR model fitted well with the adjusted $R^{2}$ greater than 0.8 when the number of selected independent variables was considered. Meanwhile, SR model of each ion was statistically significant $(p<0.001)$. Therefore, the band intervals selected by the SR models were used as the independent variables of PLSR and SVR models.

\section{Characteristic wavelength selection based on VIP method}

Curves of VIP scores of soil water-soluble salt ions content and $R_{\text {raw-SNV }}$ were shown in Fig. 5. Max VIP scores and band intervals obtained from VIP method of soil water-soluble salt ions content and $R_{\text {raw-SNV }}$ were shown in Table 5 .

The curves patterns of seven ions were similar except $\mathrm{HCO}_{3}{ }^{-}$(Fig. 5). These curves exhibited violent oscillation in the intervals of 400-800 $\mathrm{nm}$ and 1,900-2,400 nm, gentle transition between $800 \mathrm{~nm}$ and around 1,400 nm, and fluctuant rise from 1,400 to 1,900 $\mathrm{nm}$. In contrast, the curve of $\mathrm{HCO}_{3}{ }^{-}$showed oscillatory rise from 400 to $1,400 \mathrm{~nm}$, a " $U$ " shaped motion from 1,400 to $1,900 \mathrm{~nm}$ or so, and a rapid fall and oscillation to 2,400 nm. The numbers of sensitive bands based on VIP method displayed the following sequence: $\mathrm{Cl}^{-}(85)>\mathrm{Na}^{+}(83)>\mathrm{HCO}_{3}^{-}(79)>\mathrm{SO}_{4}{ }^{2-}(74)>\mathrm{Mg}^{2+}(69)=\mathrm{Ca}^{2+}(69)=\mathrm{K}^{+}(69)>$ 


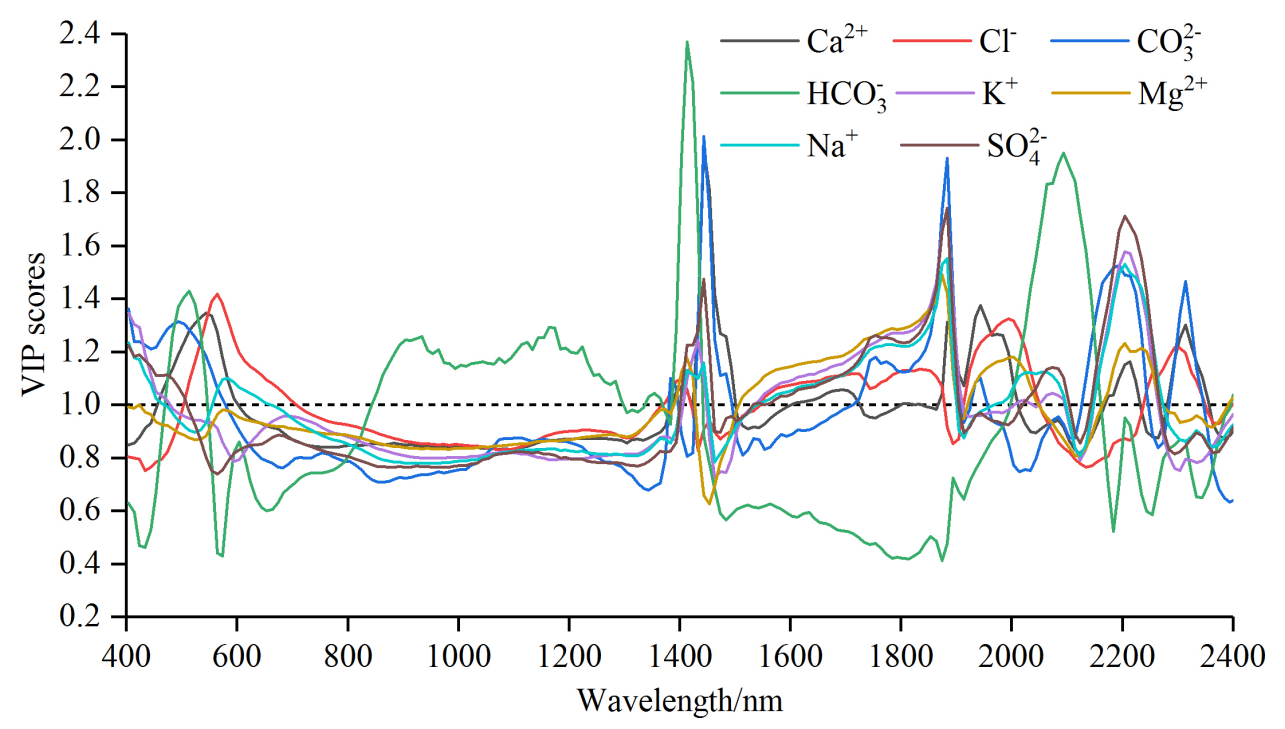

Figure 5 The Variable importance in projection (VIP) scores for soil water-soluble salt ions content with standard normal variable reflectance.

Full-size DOI: 10.7717/peerj.6310/fig-5

Table 4 Parameter indexes of feature band intervals selection by stepwise regression method.

\begin{tabular}{|c|c|c|c|c|c|}
\hline $\begin{array}{l}\text { Water-soluble } \\
\text { salt ions }\end{array}$ & $\begin{array}{l}\text { Sensitive } \\
\text { band } \\
\text { numbers }\end{array}$ & $\begin{array}{l}\text { Band } \\
\text { intervals/nm }\end{array}$ & $\begin{array}{l}\text { Adjusted } \\
R^{2}\end{array}$ & $\begin{array}{l}\text { Standard } \\
\text { error }\end{array}$ & Sig. \\
\hline $\mathrm{Ca}^{2+}$ & 7 & $\begin{array}{l}1,040 \sim 1,050,1,090 \sim 1,100, \\
1,900 \sim 1,910,1,920 \sim 1,930, \\
2,200 \sim 2,210,2,310 \sim 2,320, \\
2,370 \sim 2,380\end{array}$ & 0.942 & 0.529 & $<0.001$ \\
\hline $\mathrm{Cl}^{-}$ & 8 & $\begin{array}{l}730 \sim 740,910 \sim 920, \\
1,890 \sim 1,900,1,970 \sim 1,980, \\
1,990 \sim 2,000,2,180 \sim 2,190, \\
2,200 \sim 2,210,2,290 \sim 2,300\end{array}$ & 0.975 & 1.063 & $<0.001$ \\
\hline $\mathrm{CO}_{3}{ }^{2-}$ & 4 & $\begin{array}{l}1,280 \sim 1,290,1,360 \sim 1,370 \\
1,380 \sim 1,390,1,420 \sim 1,430\end{array}$ & 0.836 & 0.012 & $<0.001$ \\
\hline $\mathrm{HCO}_{3}{ }^{-}$ & 3 & $\begin{array}{l}2,200 \sim 2,210,2,260 \sim 2,270, \\
2,290 \sim 2,300\end{array}$ & 0.934 & 0.085 & $<0.001$ \\
\hline $\mathrm{K}^{+}$ & 6 & $\begin{array}{l}740 \sim 750,810 \sim 820, \\
1,160 \sim 1,170,1,890 \sim 1,900, \\
2,210 \sim 2,220,2,390 \sim 2,400\end{array}$ & 0.817 & 0.706 & $<0.001$ \\
\hline $\mathrm{Mg}^{2+}$ & 6 & $\begin{array}{l}1,130 \sim 1,140,1,930 \sim 1,950, \\
1,990 \sim 2,000,2,100 \sim 2,110, \\
2,170 \sim 2,180\end{array}$ & 0.973 & 0.152 & $<0.001$ \\
\hline $\mathrm{Na}^{+}$ & 6 & $\begin{array}{l}740 \sim 750,820 \sim 830, \\
1,860 \sim 1,870,2,210 \sim 2,220, \\
2,260 \sim 2,270,2,390 \sim 2,400\end{array}$ & 0.942 & 1.812 & $<0.001$ \\
\hline $\mathrm{SO}_{4}^{2-}$ & 6 & $\begin{array}{l}610 \sim 620,1,140 \sim 1,150, \\
1,960 \sim 1,970,2,210 \sim 2,220, \\
2,290 \sim 2,300,2,390 \sim 2,400\end{array}$ & 0.947 & 3.255 & $<0.001$ \\
\hline
\end{tabular}




\begin{tabular}{|c|c|c|c|}
\hline $\begin{array}{l}\text { Water-soluble } \\
\text { salt ions }\end{array}$ & $\begin{array}{l}\text { Sensitive } \\
\text { band numbers }\end{array}$ & $\begin{array}{l}\text { Maximum VIP } \\
\text { scores }\end{array}$ & $\begin{array}{l}\text { Maximum VIP scores } \\
\text { intervals/nm }\end{array}$ \\
\hline $\mathrm{Ca}^{2+}$ & 69 & 1.97 & $1,440 \sim 1,450$ \\
\hline $\mathrm{Cl}^{-}$ & 85 & 1.42 & $560 \sim 570$ \\
\hline $\mathrm{CO}_{3}{ }^{2-}$ & 67 & 2.01 & $1,440 \sim 1,450$ \\
\hline $\mathrm{HCO}_{3}{ }^{-}$ & 79 & 2.37 & $1,410 \sim 1,420$ \\
\hline $\mathrm{K}^{+}$ & 69 & 1.73 & $1,880 \sim 1,890$ \\
\hline $\mathrm{Mg}^{2+}$ & 69 & 1.49 & $1,870 \sim 1,880$ \\
\hline $\mathrm{Na}^{+}$ & 83 & 1.55 & $1,880 \sim 1,890$ \\
\hline $\mathrm{SO}_{4}{ }^{2-}$ & 74 & 1.74 & $1,880 \sim 1,890$ \\
\hline
\end{tabular}

$\mathrm{CO}_{3}{ }^{2-}$ (67). The sequence of the maximal VIP scores was $\mathrm{HCO}_{3}{ }^{-}(2.37)>\mathrm{CO}_{3}{ }^{2-}(2.01)$ $>\mathrm{Ca}^{2+}(1.97)>\mathrm{SO}_{4}{ }^{2-}(1.74)>\mathrm{K}^{+}(1.73)>\mathrm{Na}^{+}(1.55)>\mathrm{Mg}^{2+}(1.49)>\mathrm{Cl}^{-}(1.42)$. The spectral interval of the maximal VIP scores of $\mathrm{Cl}^{-}$was from 560 to $570 \mathrm{~nm}, \mathrm{Ca}^{2+}, \mathrm{CO}_{3}{ }^{2-}$ and $\mathrm{HCO}_{3}{ }^{-}$were concentrated between 1,410 and $1,450 \mathrm{~nm}$; and $\mathrm{K}^{+}, \mathrm{Mg}^{2+}, \mathrm{Na}^{+}$and $\mathrm{SO}_{4}{ }^{2-}$ were from 1,870 to $1,890 \mathrm{~nm}$.

\section{Construction and analysis of PLSR model}

The sensitive bands were obtained using different band selection methods of GC, SR and VIP to build PLSR model. The results of PLSR model were shown in Table 6.

The models of the six ions $\mathrm{Ca}^{2+}, \mathrm{Cl}^{-}, \mathrm{CO}_{3}{ }^{2-}, \mathrm{Mg}^{2+}, \mathrm{Na}^{+}$and $\mathrm{SO}_{4}{ }^{2-}$ performed well using VIP method $\left(R_{c}{ }^{2}\right.$ is close to 1). The models based on the bands of $\mathrm{Ca}^{2+}, \mathrm{Cl}^{-}, \mathrm{Mg}^{2+}$, $\mathrm{Na}^{+}$and $\mathrm{SO}_{4}{ }^{2-}$ selected using the SR method displayed good fitting effect, and those of $\mathrm{Ca}^{2+}, \mathrm{Mg}^{2+}$ and $\mathrm{Na}^{+}$using the GC method exhibited good fitting effect.

In terms of verification accuracy, VIP method had excellent prediction of $\mathrm{Ca}^{2+}, \mathrm{Na}^{+}$, $\mathrm{SO}_{4}{ }^{2-}$, SR method had excellent prediction of $\mathrm{Ca}^{2+}, \mathrm{Mg}^{2+}, \mathrm{Na}^{+}, \mathrm{SO}_{4}{ }^{2-}$ (the RPD of $\mathrm{Ca}^{2+}$ was up to 3.95), and GC method did not show strong prediction power over any ions. On the contrary, all the three models demonstrated poor forecasting power over $\mathrm{HCO}_{3}{ }^{-}$. The RPDs of SR- $\mathrm{HCO}_{3}{ }^{-}$and VIP- $\mathrm{HCO}_{3}{ }^{-}$were 0.64 and 0.93 respectively. Therefore, VIP method had the best modeling effect and SR method had the best forecasting effect, and GC method had poor modeling and forecasting effects on the salt ions inversion in the PLSR model.

\section{Construction and analysis of SVR model}

The sensitive bands were obtained by using different band selection methods of GC, SR and VIP to build SVR model. The results of SVR model were shown in Table 7.

The modeling accuracy of SVR model was similar to that of PLSR model. But the verification accuracy of ions was different between the two models. VIP method had the excellent prediction of $\mathrm{Ca}^{2+}, \mathrm{Cl}^{-}, \mathrm{Mg}^{2+}, \mathrm{Na}^{+}$, SR method had the excellent prediction of $\mathrm{Ca}^{2+}, \mathrm{Mg}^{2+}, \mathrm{Na}^{+}, \mathrm{SO}_{4}{ }^{2-}$, and GC method did not show strong prediction power over any ions. The prediction results of $\mathrm{Ca}^{2+}$ were the best: the RPD of VIP and SR models were 3.93 and 3.97, respectively. Overall, in the SVR model, VIP method exhibited the best 
Table 6 Calibration and validation results of soil water-soluble salt ions content from the PLSR inversion models using the GC, SR and VIP wavelength selection methods.

\begin{tabular}{|c|c|c|c|c|c|c|}
\hline \multirow{2}{*}{$\begin{array}{l}\text { Wavelength } \\
\text { selection methods }\end{array}$} & \multirow{2}{*}{$\begin{array}{l}\text { Water-soluble } \\
\text { salt ions }\end{array}$} & \multirow{2}{*}{$\begin{array}{l}\text { Latent } \\
\text { variables }\end{array}$} & \multirow{2}{*}{$\begin{array}{l}\text { Calibration } \\
\text { sets } \\
R_{c}{ }^{2}\end{array}$} & \multicolumn{3}{|c|}{ Validation sets } \\
\hline & & & & $R_{p}{ }^{2}$ & $\mathrm{RMSE} /\left(\mathrm{g} \mathrm{kg}^{-1}\right)$ & RPD \\
\hline \multirow{8}{*}{$\begin{array}{l}\text { Gray } \\
\text { correlation }\end{array}$} & $\mathrm{Ca}^{2+}$ & 7 & 0.897 & 0.724 & 0.362 & 1.71 \\
\hline & $\mathrm{Cl}^{-}$ & 7 & 0.796 & 0.565 & 3.150 & 1.35 \\
\hline & $\mathrm{CO}_{3}{ }^{2-}$ & 5 & 0.660 & 0.649 & 0.012 & 1.21 \\
\hline & $\mathrm{HCO}_{3}{ }^{-}$ & 7 & 0.646 & 0.285 & 0.088 & 0.96 \\
\hline & $\mathrm{K}^{+}$ & 1 & 0.388 & 0.258 & 1.209 & 0.85 \\
\hline & $\mathrm{Mg}^{2+}$ & 6 & 0.891 & 0.767 & 0.295 & 1.99 \\
\hline & $\mathrm{Na}^{+}$ & 7 & 0.840 & 0.805 & 2.589 & 1.88 \\
\hline & $\mathrm{SO}_{4}{ }^{2-}$ & 4 & 0.561 & 0.360 & 8.711 & 0.87 \\
\hline \multirow{8}{*}{$\begin{array}{l}\text { Stepwise } \\
\text { regression }\end{array}$} & $\mathrm{Ca}^{2+}$ & 7 & 0.965 & 0.937 & 0.168 & 3.95 \\
\hline & $\mathrm{Cl}^{-}$ & 2 & 0.861 & 0.729 & 2.434 & 1.80 \\
\hline & $\mathrm{CO}_{3}{ }^{2-}$ & 4 & 0.685 & 0.742 & 0.010 & 1.80 \\
\hline & $\mathrm{HCO}_{3}{ }^{-}$ & 3 & 0.340 & 0.154 & 0.094 & 0.64 \\
\hline & $\mathrm{K}^{+}$ & 5 & 0.722 & 0.563 & 0.931 & 1.37 \\
\hline & $\mathrm{Mg}^{2+}$ & 4 & 0.933 & 0.849 & 0.236 & 2.52 \\
\hline & $\mathrm{Na}^{+}$ & 3 & 0.901 & 0.868 & 2.145 & 2.67 \\
\hline & $\mathrm{SO}_{4}^{2-}$ & 5 & 0.918 & 0.889 & 3.807 & 2.75 \\
\hline \multirow{8}{*}{$\begin{array}{l}\text { Variable } \\
\text { importance } \\
\text { in } \\
\text { projection }\end{array}$} & $\mathrm{Ca}^{2+}$ & 3 & 0.909 & 0.865 & 0.249 & 2.57 \\
\hline & $\mathrm{Cl}^{-}$ & 4 & 0.930 & 0.862 & 1.725 & 2.48 \\
\hline & $\mathrm{CO}_{3}{ }^{2-}$ & 9 & 0.865 & 0.617 & 0.012 & 1.44 \\
\hline & $\mathrm{HCO}_{3}^{-}$ & 9 & 0.704 & 0.263 & 0.090 & 0.93 \\
\hline & $\mathrm{K}^{+}$ & 5 & 0.664 & 0.566 & 0.945 & 1.43 \\
\hline & $\mathrm{Mg}^{2+}$ & 3 & 0.910 & 0.840 & 0.243 & 2.34 \\
\hline & $\mathrm{Na}^{+}$ & 8 & 0.939 & 0.902 & 1.801 & 3.15 \\
\hline & $\mathrm{SO}_{4}{ }^{2-}$ & 8 & 0.919 & 0.872 & 4.038 & 2.75 \\
\hline
\end{tabular}

performance for modeling and predicting the salt ions content, SR method was the second, and GC method was relatively poorer.

\section{DISCUSSION}

\section{Comparison among the results of different salt ions content in estimating}

The optimal band selection method varied in some degree from the optimal modeling method (Tables 6 and 7). The comparison was made between the measured value and the estimated value of all the ions concerned under the optimal model (Fig. 6). The sequence of the forecasting power of the ions was $\mathrm{Ca}^{2+}>\mathrm{Na}^{+}>\mathrm{Cl}^{-}>\mathrm{Mg}^{2+}>\mathrm{SO}_{4}{ }^{2-}>\mathrm{CO}_{3}{ }^{2-}>$ $\mathrm{K}^{+}>\mathrm{HCO}_{3}{ }^{-}$, and it was the same as that of the modeling power.

Obviously, the verification result showed that most data points of the five ions, $\mathrm{Ca}^{2+}$, $\mathrm{Na}^{+}, \mathrm{Cl}^{-}, \mathrm{Mg}^{2+}$ and $\mathrm{SO}_{4}{ }^{2-}$, were concentrated near line 1:1. The optimal models of these five ions had very strong predicative power with the RPD above 2.5 (Tables 6 and 7). 
Table 7 Calibration and validation results of soil water-soluble salt ions content from the SVR inversion models using the GC, SR and VIP wavelength selection methods.

\begin{tabular}{|c|c|c|c|c|c|}
\hline \multirow{2}{*}{$\begin{array}{l}\text { Wavelength } \\
\text { selection methods }\end{array}$} & \multirow{2}{*}{$\begin{array}{l}\text { Water-soluble } \\
\text { salt ions }\end{array}$} & \multirow{2}{*}{$\begin{array}{l}\text { Calibration } \\
\text { sets } \\
R_{c}{ }^{2}\end{array}$} & \multicolumn{2}{|c|}{ Validation sets } & \multirow[b]{2}{*}{ RPD } \\
\hline & & & $R_{p}{ }^{2}$ & $\mathrm{RMSE} /\left(\mathrm{g} \mathrm{kg}^{-1}\right)$ & \\
\hline \multirow{8}{*}{$\begin{array}{l}\text { Gray } \\
\text { correlation }\end{array}$} & $\mathrm{Ca}^{2+}$ & 0.910 & 0.752 & 0.337 & 1.73 \\
\hline & $\mathrm{Cl}^{-}$ & 0.652 & 0.500 & 3.275 & 1.05 \\
\hline & $\mathrm{CO}_{3}^{2-}$ & 0.688 & 0.664 & 0.012 & 1.14 \\
\hline & $\mathrm{HCO}_{3}{ }^{-}$ & 0.563 & 0.328 & 0.083 & 0.70 \\
\hline & $\mathrm{K}^{+}$ & 0.421 & 0.269 & 1.155 & 0.61 \\
\hline & $\mathrm{Mg}^{2+}$ & 0.934 & 0.781 & 0.289 & 2.07 \\
\hline & $\mathrm{Na}^{+}$ & 0.809 & 0.764 & 2.851 & 1.85 \\
\hline & $\mathrm{SO}_{4}^{2-}$ & 0.565 & 0.397 & 9.046 & 0.52 \\
\hline \multirow{8}{*}{$\begin{array}{l}\text { Stepwise } \\
\text { regression }\end{array}$} & $\mathrm{Ca}^{2+}$ & 0.964 & 0.940 & 0.164 & 3.97 \\
\hline & $\mathrm{Cl}^{-}$ & 0.893 & 0.790 & 2.186 & 2.15 \\
\hline & $\mathrm{CO}_{3}{ }^{2-}$ & 0.605 & 0.583 & 0.013 & 1.16 \\
\hline & $\mathrm{HCO}_{3}{ }^{-}$ & 0.327 & 0.164 & 0.095 & 0.56 \\
\hline & $\mathrm{K}^{+}$ & 0.717 & 0.578 & 0.874 & 1.26 \\
\hline & $\mathrm{Mg}^{2+}$ & 0.936 & 0.875 & 0.214 & 2.75 \\
\hline & $\mathrm{Na}^{+}$ & 0.903 & 0.864 & 2.171 & 2.61 \\
\hline & $\mathrm{SO}_{4}{ }^{2-}$ & 0.915 & 0.893 & 3.862 & 2.71 \\
\hline \multirow{8}{*}{$\begin{array}{l}\text { Variable } \\
\text { importance } \\
\text { in } \\
\text { projection }\end{array}$} & $\mathrm{Ca}^{2+}$ & 0.960 & 0.935 & 0.173 & 3.93 \\
\hline & $\mathrm{Cl}^{-}$ & 0.949 & 0.897 & 1.483 & 2.98 \\
\hline & $\mathrm{CO}_{3}^{2-}$ & 0.883 & 0.664 & 0.012 & 1.56 \\
\hline & $\mathrm{HCO}_{3}^{-}$ & 0.669 & 0.280 & 0.088 & 0.91 \\
\hline & $\mathrm{K}^{+}$ & 0.645 & 0.565 & 0.888 & 1.23 \\
\hline & $\mathrm{Mg}^{2+}$ & 0.965 & 0.877 & 0.214 & 2.51 \\
\hline & $\mathrm{Na}^{+}$ & 0.958 & 0.872 & 2.211 & 2.76 \\
\hline & $\mathrm{SO}_{4}^{2-}$ & 0.914 & 0.865 & 4.106 & 2.48 \\
\hline
\end{tabular}

Compared with the previous researches, model prediction effects of $\mathrm{K}^{+}$and $\mathrm{Na}^{+}$(Qu et al., 2009); $\mathrm{Ca}^{2+}, \mathrm{Na}^{+}$and $\mathrm{Mg}^{2+}$ (Viscarra Rossel \& Webster, 2012); $\mathrm{HCO}_{3}{ }^{-}, \mathrm{Ca}^{2+}, \mathrm{Cl}^{-}, \mathrm{Mg}^{2+}$ and $\mathrm{SO}_{4}{ }^{2-}$ (Dai et al., 2015); $\mathrm{HCO}_{3}{ }^{-}, \mathrm{Ca}^{2+}$ and $\mathrm{SO}_{4}{ }^{2-}$ (Peng et al., 2016a); $\mathrm{K}^{+}, \mathrm{Na}^{+}, \mathrm{Ca}^{2+}$ and $\mathrm{SO}_{4}{ }^{2-}$ (Wang et al., 2018a) were satisfactory. Although the results of this study are not exactly the same as these previous researches, it still shows the rationality own to some extent. In addition, this result shows that band selection has realized the goal of removing the irrelevant information, and plays a major role in improving the inversion accuracy of salt ions.

In Fig. 6, the data points of $\mathrm{CO}_{3}{ }^{2-}$ and $\mathrm{K}^{+}$were relatively dispersed in the verification result. The $\mathrm{CO}_{3}{ }^{2-}$ had a relatively good predictive power $(\mathrm{RPD}=1.80)$ and the $\mathrm{K}^{+}$had a normal predictive power $(\mathrm{RPD}=1.43)$. Notably, $\mathrm{HCO}_{3}{ }^{-}$had no predicative power $(\mathrm{RPD}=0.96)$ because the slope was under the 1:1 line and the data points were most discrete (Fig. 6D). The predicting effect of $\mathrm{HCO}_{3}{ }^{-}$was different from that of Peng et al. (2016a) and Dai et al. (2015), but similar to that of Wang et al. (2018a). The cause of this 

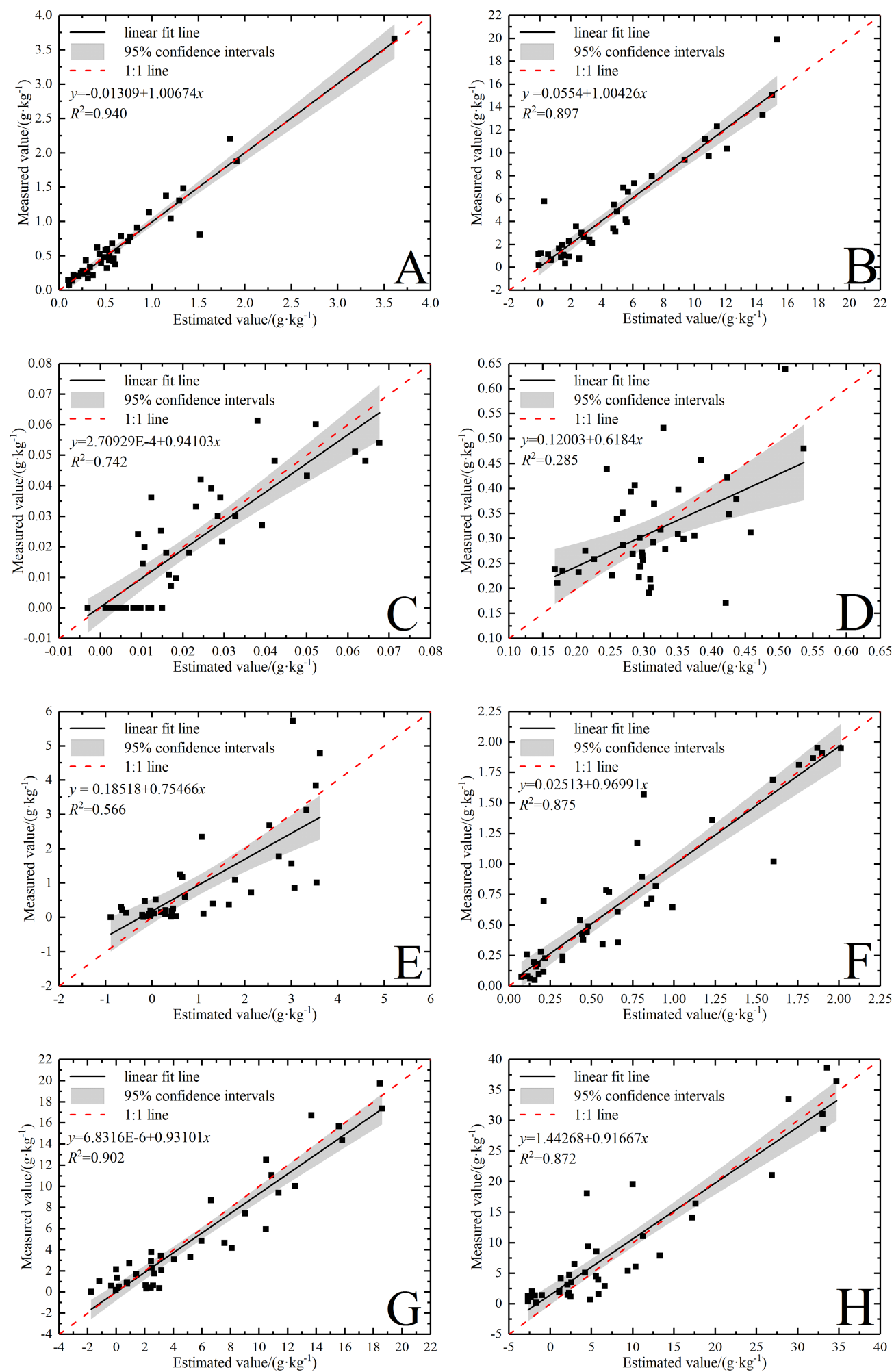

Figure 6 Validation of soil water-soluble salt ions content based on the best model. (A) $\mathrm{Ca}^{2+}$ with SRSVR model. (B) $\mathrm{Cl}^{-}$with VIP-SVR model. (C) $\mathrm{CO}_{3}^{2-}$ with SR-PLSR model. (D) $\mathrm{HCO}_{3}^{-}$with GC-PLSR model. (E) $\mathrm{K}^{+}$with VIP-PLSR model. (F) $\mathrm{Mg}^{2+}$ with SR-SVR model. (G) $\mathrm{Na}^{+}$with VIP-PLSR model. (H) $\mathrm{SO}_{4}^{2-}$ with VIP-PLSR model.

Full-size DOI: 10.7717/peerj.6310/fig-6 
result needs to be further studied. Overall, it is vital to make some efforts to improve the robustness and accuracy of these ion models. Xiao, Li \& Feng (2016b) failed to predict $\mathrm{Na}^{+}, \mathrm{Mg}^{2+}$ and $\mathrm{Ca}^{2+}$, but applied the SVR model to forecasting SAR after the SNV transformation and the performance was satisfactory $(\mathrm{RPD}=2.13)$. Analogously, first derivative reflectance (FDR) index was calculated to effectively predict SAR by Xiao, $\mathrm{Li}$ \& Feng (2016a). In addition, Viscarra Rossel \& Webster (2012) forecasted the content of $\mathrm{Na}^{+}$ after logarithmic pretreatment with VIS-NIR spectral technique (RPD = 2.10). Thus, salt ion indexes construction and variable transformation processing are helpful approaches to improve the correlation with the spectra so as to establish satisfactory models.

A little difference existed in the applicability between PLSR and SVR models on inversing the content of ions. Both methods could produce satisfactory results in conformity with that of Peng et al. (2016a). In addition, the optimal inversion models and prediction models for each ion were different: SR-PLSR model and SR-SVR model for $\mathrm{Ca}^{2+}$, VIPSVR model and SR-PLSR model for $\mathrm{CO}_{3}{ }^{2-}$, SR-PLSR model and VIP-PLSR model for $\mathrm{K}^{+}$, VIP-PLSR model and GC-PLSR model for $\mathrm{HCO}_{3}{ }^{-}$, respectively. Among them, the performance of the optimal inversion model of $\mathrm{Ca}^{2+}$ resembled that of the prediction model. The results suggested that the ion models with poorer performance frequently demonstrated uncertainty in the inversion process (Peng et al., 2016a). Generally, as the major water-soluble ion components in the two highly soluble salts of sodium and kali, $\mathrm{Na}^{+}$ and $\mathrm{K}^{+}$exhibit great difference in the spectral characterization degree (Dai et al., 2015). Therefore, the spectral characters of water-soluble salt ions are not necessarily determined by the number of dissociative ions, so more pertinent experiments and analysis should be conducted to explore the response mechanism.

\section{Correlation analysis and inversion performance}

The raw spectral reflectance curve of each soil sample presented distinct shapes (Fig. 2A). One of the prime reasons for this phenomenon is that the absorption features in these soil samples were related to soil salt crystal contents and types, as well as various chemical bonds (e.g., C-H, O-H, N-H). The results were in accordance with those in previous studies (Viscarra Rossel et al., 2006; Viscarra Rossel \& Webster, 2012; Dai et al., 2015; Peng et al., 2016a; Wang et al., 2018a), which demonstrated that soil VIS-NIR spectra could be used to determine part of soil salt ions contents in some degree.

Traditionally, correlation analysis helps reveal the relationships between soil salt ions content and VIS-NIR spectra, and it indicates modeling effects to some degree (Weng, Gong $\& Z h u, 2008)$. In the current research, the number of the significant bands of different ions could be sequenced from the largest to the smallest as follows: $\mathrm{Cl}^{-}(96 \%)>\mathrm{Ca}^{2+}(95 \%)$ $>\mathrm{Mg}^{2+}(93 \%)>\mathrm{Na}^{+}(90.5 \%)>\mathrm{K}^{+}(89 \%)=\mathrm{SO}_{4}{ }^{2-}(89 \%)>\mathrm{CO}_{3}{ }^{2-}(73 \%)>\mathrm{HCO}_{3}{ }^{-}$ $(0.5 \%)$, the correlation coefficients of different ions ranged from the largest to the smallest as: $\mathrm{Cl}^{-}(-0.882)>\mathrm{Ca}^{2+}(-0.877)>\mathrm{Mg}^{2+}(-0.848)>\mathrm{Na}^{+}(-0.752)>\mathrm{SO}_{4}{ }^{2-}(0.749)$ $>\mathrm{K}^{+}(0.630)>\mathrm{CO}_{3}{ }^{2-}(0.552)>\mathrm{HCO}_{3}^{-}(0.235)$ (Table 2). Thereby, five ions $\left(\mathrm{Cl}^{-}\right.$, $\mathrm{Ca}^{2+}, \mathrm{Mg}^{2+}, \mathrm{Na}^{+}$and $\mathrm{SO}_{4}{ }^{2-}$ ) had more significant relationship with reflectance spectra. Although there were some differences between forecasting power ranking and correlation ranking, the optimal models of these five ions had the excellent predictive results (Fig. 6). 
Nevertheless, the other three ions $\left(\mathrm{K}^{+}, \mathrm{CO}_{3}{ }^{2-}\right.$ and $\left.\mathrm{HCO}_{3}{ }^{-}\right)$had weak correlations and unsatisfactory predictive power. In particular, $\mathrm{HCO}_{3}{ }^{-}$had only one significant band and the worst prediction effects. But in most cases, the sensitive band numbers of $\mathrm{HCO}_{3}{ }^{-}$ were not the least in comparing the results of the three wavelength selection methods (Tables 3-5). Thus, we conjecture that the different calculation mechanisms cause a certain inconsistency between modeling performance and sensitivity. In addition, the optimal method of finding out their responding spectrum varies from one ion to another in the soil. In future study, it is practically significant to adopt various methods to select the optimal bands in the inversion of soil ions.

\section{Effects of wavelength selection on estimation models}

The massive complex spectra often contain a large amount of redundant information irrelevant to the ions contents. The selection of feature spectra is hence a critical step to create a robust model. From Tables 3-5, we could see the great difference exist in the number of wavelength selected with the three methods: VIP method had the largest number of wavelengths $(34.5 \% \sim 42.5 \%)$, SR method had the smallest number of wavelengths $(1.5 \% \sim 4 \%)$ and number of wavelengths $(7 \% \sim 55 \%)$ varied greatly by GC method.

Our experiment with three wavelength selection methods also indicated that different methods yielded different results. Among the three methods, the VIP method produced the best results, followed by SR method, while the GC method performed least ideally. We argue that the GC method is not necessarily an inappropriate method as some results are still acceptable. However, GC method could distinguish the primary relationships among the factors in the system by calculating and comparing GCD (Deng, 1982; Liu, Yang \& $W u, 2015)$. In the field of spectral analysis, the application of GC method could better identify sensitive spectral indices, select sensitive bands and optimize inversion model ( $\mathrm{Li}$ et al., 2016). On the other hand, Wang et al. (2018b) used GC method to extract the feature bands of soil organic matter content to construct the model with stronger generalization capability. Therefore, the soil compositions have a strong impact on the performance of spectral model. This conclusion is consistent with previous research results (Viscarra Rossel et al., 2006; Viscarra Rossel \& Webster, 2012; Xiao, Li \& Feng, 2016b). The VIP values were calculated with VIP method, in the process of PLSR analysis to further evaluate the significance of each wavelength for model prediction (Wold, Sjöström \& Eriksson, 2001; Maimaitiyiming et al., 2017; Qi et al., 2017). VIP method often produces the best results in the modeling set because it can distinguish between useful information and inevitable noises in the set. Oussama et al. (2012) adopted this method to reduce almost 75\% of the total data set for a simplified model of high accuracy. Additionally, as a simplified regression linear model, SR method not only preserves significant bands but also solves multicollinearity problems effectively (Xiao, Li \& Feng, 2016a; Xiao, Li \& Feng, 2016b). It has great optimization effect on model complexity by adjusting the significance level of selected and excluded variables (Zhang et al., 2018). Compared with the selection results with VIP method, SR method could be used to extract fewer bands to establish ions (except for $\mathrm{K}^{+}, \mathrm{CO}_{3}{ }^{2-}$ and $\mathrm{HCO}_{3}{ }^{-}$) forecasting models with RPD above 1.80. Therefore, it is meaningful to make further simplification of the model while ensuring its accuracy. 


\section{Research limitations}

This study clearly demonstrated that VIS-NIR spectral analysis technique is an effective method to detect salt ions content of salinity soil in the irrigated district. In terms of extracting feature wavelengths to estimate ions content, our work provides a comprehensive comparison and evaluation approaches. Such endeavor is critically and practically important to further enhance the model performance of the soil salt ions. The application of machine learning algorithms with strong applicability to solve nonlinear relationship between variables, such as Ant Colony Optimization-interval Partial Least Square (ACOiPLS), Recursive Feature Elimination based on Support Vector Machine (RF-SVM), and Random Forest (RF) has been proved to be a useful approach to obtain the effective information of soil organic matter (Ding et al., 2018). To further improve the prediction accuracy, the more machine learning algorithms should be applied to the analysis of sensitive spectral regions and the construction of stable models in future study. In addition, the application of multi-source remote sensing platforms such as Landsat, GaoFen-5, Hyperion and unmanned aerial vehicle (UAV) in soil salt ions estimation has not been investigated. Therefore, further research should focus on the possible combination of multiple approaches and remote sensing data at different scales to estimate soil salt ions content.

\section{CONCLUSIONS}

This study investigated the feasibility of estimating soil water-soluble salt ions content via VIS-NIR spectral model. Different methods were applied to the selection of response bands interval to construct robust inversion models. Among them, VIP method could select larger number of wavebands with the highest accuracy, SR method could select the smallest number of wavebands with good accuracy. However, the number of wavebands obtained using the GC method varied greatly with poor accuracy. The PLSR and SVR models achieved good effects on the modeling and forecasting of most ions content. Moreover, the PLSR model was slightly more than the SVR model in terms of the number of ion models with good predictive effects (RPD over 2.0). The models of $\mathrm{Ca}^{2+}, \mathrm{Na}^{+}, \mathrm{Cl}^{-}$, $\mathrm{Mg}^{2+}$ and $\mathrm{SO}_{4}{ }^{2-}$ displayed the highest prediction accuracy, and the RPDs were 3.97, 3.15, 2.98, 2.75 and 2.75, respectively, while those of other ions were poor. Overall, the best wavelength selection methods, models and inversion results of soil salt ions were different. In the future, the combination of band selection methods and spectral model will have a great potential for predicting some soil salt ions content in the salinization area. Such an approach can be utilized to assist decision makers toward the determination of soil salinization levels.

\section{ACKNOWLEDGEMENTS}

The authors want to thank Associate Professor Junying Chen for her help in language standardization of this manuscript and providing helpful suggestions. We are especially grateful to the reviewers and editors for appraising our manuscript and for offering 
instructive comments. In addition, Haifeng Wang especially wishes to thank JJ Lin, who has given him powerful spiritual encouragement over the past time.

\section{ADDITIONAL INFORMATION AND DECLARATIONS}

\section{Funding}

The research is supported by the National Key Research and Development Program of China (2017YFC0403302, 2016YFD0200700). Support also came from the Science and Technology Plan Project of Yangling (2018GY-03) and the Humanities and Social Science Program of Northwest A\&F University (Z109021405). The funders had no role in study design, data collection and analysis, decision to publish, or preparation of the manuscript.

\section{Grant Disclosures}

The following grant information was disclosed by the authors:

National Key Research and Development Program of China: 2017YFC0403302, 2016YFD0200700.

Science and Technology Plan Project of Yangling: 2018GY-03.

Humanities and Social Science Program of Northwest A\&F University: Z109021405.

\section{Competing Interests}

The authors declare there are no competing interests.

\section{Author Contributions}

- Haifeng Wang conceived and designed the experiments, performed the experiments, analyzed the data, prepared figures and/or tables, authored or reviewed drafts of the paper, approved the final draft.

- Yinwen Chen conceived and designed the experiments, prepared figures and/or tables, authored or reviewed drafts of the paper.

- Zhitao Zhang conceived and designed the experiments, authored or reviewed drafts of the paper, approved the final draft.

- Haorui Chen contributed reagents/materials/analysis tools, approved the final draft.

- Xianwen Li contributed reagents/materials/analysis tools.

- Mingxiu Wang performed the experiments, analyzed the data.

- Hongyang Chai performed the experiments.

\section{Field Study Permissions}

The following information was supplied relating to field study approvals (i.e., approving body and any reference numbers):

The Hetao irrigation district administration approved the field sampling (2017YFC0403302).

\section{Data Availability}

The following information was supplied regarding data availability:

The raw data are available in the Supplemental File. 


\section{Supplemental Information}

Supplemental information for this article can be found online at http://dx.doi.org/10.7717/ peerj.6310\#supplemental-information.

\section{REFERENCES}

Abbas A, Khan S, Hussain N, Hanjra MA, Akbar S. 2013. Characterizing soil salinity in irrigated agriculture using a remote sensing approach. Physics and Chemistry of the Earth 55-57:43-52 DOI 10.1016/j.pce.2010.12.004.

Aboukila EF, Norton JB. 2017. Estimation of saturated soil paste salinity from soil-water extracts. Soil Science 182:107-113 DOI 10.1097/SS.0000000000000197.

Al-Khaier F. 2003. Soil salinity detection using satellite remote sensing. Enschede, The Netherlands: International Institute for Geo-Information Science and Earth Observation.

Bannari A, El-Battay A, Bannari R, Rhinane H. 2018. Sentinel-MSI VNIR and SWIR bands sensitivity analysis for soil salinity discrimination in an arid landscape. Remote Sensing 10:Article 855 DOI 10.3390/rs10060855.

Bao S. 2000. Soil and agricultural chemistry analysis. Beijing: China Agriculture Press (in Chinese).

Barnes RJ, Dhanoa MS, Lister SJ. 1989. Standard normal variate transformation and de-trending of near-infrared diffuse reflectance spectra. Applied Spectroscopy 43:772-777 DOI 10.1366/0003702894202201.

Ben-Dor E. 2002. Quantitative remote sensing of soil properties. Advances in Agronomy 75:173-243 DOI 10.1016/S0065-2113(02)75005-0.

Ben-Dor E, Chabrillat S, Demattê JAM, Taylor GR, Hill J, Whiting ML, Sommer S. 2009. Using imaging spectroscopy to study soil properties. Remote Sensing of Environment 113:S38-S55 DOI 10.1016/j.rse.2008.09.019.

Cécillon L, Barthès BG, Gomez C, Ertlen D, Genot V, Hedde M, Stevens A, Brun JJ. 2009. Assessment and monitoring of soil quality using near-infrared reflectance spectroscopy (NIRS). European Journal of Soil Science 60:770-784 DOI 10.1111/j.1365-2389.2009.01178.x.

Chen H, Zhao G, Sun L, Wang R, Liu Y. 2016. Prediction of soil salinity using nearinfrared reflectance spectroscopy with nonnegative matrix factorization. Applied Spectroscopy 70:1589-1597 DOI 10.1177/0003702816662605.

Dai X, Zhang Y, Peng J, Luo H, Xiang H. 2015. Prediction and validation of watersoluble salt ions content using hyperspectral data. Transactions of the Chinese Society of Agricultural Engineering 31:139-145 (in Chinese)

DOI 10.11975/j.issn.1002-6819.2015.22.019.

Dehaan RL, Taylor GR. 2002. Field-derived spectra of salinized soils and vegetation as indicators of irrigation-induced soil salinization. Remote Sensing of Environment 80:406-417 DOI 10.1016/S0034-4257(01)00321-2.

Deng J. 1982. Control problems of grey systems. Systems \& Control Letters 1:288-294 DOI 10.1016/S0167-6911(82)80025-X. 
Ding J, Yang A, Wang J, Sagan V, Yu D. 2018. Machine-learning-based quantitative estimation of soil organic carbon content by VIS/NIR spectroscopy. PeerJ 6:e5714 DOI 10.7717/peerj.5714.

Ding J, Yu D. 2014. Monitoring and evaluating spatial variability of soil salinity in dry and wet seasons in the Werigan-Kuqa Oasis, China, using remote sensing and electromagnetic induction instruments. Geoderma 235-236:316-322 DOI 10.1016/j.geoderma.2014.07.028.

Farifteh J, Van der Meer F, Atzberger C, Carranza EJM. 2007. Quantitative analysis of salt-affected soil reflectance spectra: a comparison of two adaptive methods (PLSR and ANN). Remote Sensing of Environment 110:59-78 DOI 10.1016/j.rse.2007.02.005.

Farifteh J, Van der Meer F, Van der Meijde M, Atzberger C. 2008. Spectral characteristics of salt-affected soils: a laboratory experiment. Geoderma 145:196-206 DOI 10.1016/j.geoderma.2008.03.011.

Gao X, Huo Z, Bai Y, Feng S, Huang G, Shi H, Qu Z. 2015. Soil salt and groundwater change in flood irrigation field and uncultivated land: a case study based on 4-year field observations. Environmental Earth Sciences 73:2127-2139 DOI 10.1007/s12665-014-3563-4.

Gomez C, Viscarra Rossel RA, McBratney AB. 2008. Soil organic carbon prediction by hyperspectral remote sensing and field vis-NIR spectroscopy: an Australian case study. Geoderma 146:403-411 DOI 10.1016/j.geoderma.2008.06.011.

Graciela M, Alfred Z. 2009. Remote sensing of soil salinization: impact on land management. Boca Raton: CRC Press.

Hong Y, Chen Y, Yu L, Liu Y, Liu Y, Zhang Y, Liu Y, Cheng H. 2018a. Combining fractional order derivative and spectral variable selection for organic matter estimation of homogeneous soil samples by VIS-NIR spectroscopy. Remote Sensing 10:Article 479 DOI 10.3390/rs10030479.

Hong Y, Yu L, Chen Y, Liu Y, Liu Y, Liu Y, Cheng H. 2018b. Prediction of soil organic matter by VIS-NIR spectroscopy using normalized soil moisture index as a proxy of soil moisture. Remote Sensing 10:Article 28 DOI 10.3390/rs10010028.

Ji W, Adamchuk VI, Biswas A, Dhawale NM, Sudarsan B, Zhang Y, Viscarra Rossel RA, Shi Z. 2016. Assessment of soil properties in situ using a prototype portable MIR spectrometer in two agricultural fields. Biosystems Engineering 152:14-27 DOI 10.1016/j.biosystemseng.2016.06.005.

Jiang H, Shu H, Lei L, Xu J. 2017. Estimating soil salt components and salinity using hyperspectral remote sensing data in an arid area of China. Journal of Applied Remote Sensing 11:Article 016043 DOI 10.1117/1.JRS.11.016043.

Jin P, Li P, Wang Q, Pu Z. 2015. Developing and applying novel spectral feature parameters for classifying soil salt types in arid land. Ecological Indicators 54:116-123 DOI 10.1016/j.ecolind.2015.02.028.

Kennard RW, Stone LA. 1969. Computer aided design of experiments. Technometrics 11:137-148 DOI 10.1080/00401706.1969.10490666. 
Li J, Pu L, Han M, Zhu M, Zhang R, Xiang Y. 2014. Soil salinization research in China: advances and prospects. Journal of Geographical Sciences 24:943-960 DOI 10.1007/s11442-014-1130-2.

Li M, Li X, Tian Y, Wu B, Zhang S. 2016. Grey relation estimating pattern of soil organic matter with residual modification based on hyper-spectral data. The Journal of Grey System 28:27-39.

Liu S, Yang Y, Wu L. 2015. Grey system theory and its application. Beijing: Science Press (in Chinese).

Maimaitiyiming M, Ghulam A, Bozzolo A, Wilkins JL, Kwasniewski MT. 2017. Early detection of plant physiological responses to different levels of water stress using reflectance spectroscopy. Remote Sensing 9:Article 745 DOI 10.3390/rs9070745.

Metternicht GI, Zinck JA. 2003. Remote sensing of soil salinity: potentials and constraints. Remote Sensing of Environment 85:1-20

DOI 10.1016/S0034-4257(02)00188-8.

Munns R. 2002. Comparative physiology of salt and water stress. Plant, Cell and Environment 25:239-250 DOI 10.1046/j.0016-8025.2001.00808.x.

Nawar S, Buddenbaum H, Hill J. 2015. Estimation of soil salinity using three quantitative methods based on visible and near-infrared reflectance spectroscopy: a case study from Egypt. Arabian Journal of Geosciences 8:5127-5140 DOI 10.1007/s12517-014-1580-y.

Nawar S, Buddenbaum H, Hill J, Kozak J. 2014. Modeling and mapping of soil salinity with reflectance spectroscopy and landsat data using two quantitative methods (PLSR and MARS). Remote Sensing 6:10813-10834 DOI 10.3390/rs61110813.

Oussama A, Elabadi F, Platikanov S, Kzaiber F, Tauler R. 2012. Detection of olive oil adulteration using FT-IR spectroscopy and PLS with variable importance of projection (VIP) scores. Journal of the American Oil Chemists Society 89:1807-1812 DOI 10.1007/s11746-012-2091-1.

Peng J, Ji W, Ma Z, Li S, Chen S, Zhou L, Shi Z. 2016a. Predicting total dissolved salts and soluble ion concentrations in agricultural soils using portable visible nearinfrared and mid-infrared spectrometers. Biosystems Engineering 152:94-103 DOI 10.1016/j.biosystemseng.2016.04.015.

Peng X, Xu C, Zeng W, Wu J, Huang J. 2016b. Elimination of the soil moisture effect on the spectra for reflectance prediction of soil salinity using external parameter orthogonalization method. Journal of Applied Remote Sensing 10:Article 015014 DOI 10.1117/1.JRS.10.015014.

Periasamy S, Shanmugam RS. 2017. Multispectral and microwave remote sensing models to survey soil moisture and salinity. Land Degradation \& Development 28:1412-1425 DOI 10.1002/ldr.2661.

Qi H, Tarin P, Arnon K, Li S. 2017. Linear multi-task learning for predicting soil properties using field spectroscopy. Remote Sensing 9:Article 1099 DOI 10.3390/rs9111099. 
Qu Y, Duan X, Gao H, Chen A, An Y, Song J, Zhou H, He T. 2009. Quantitative retrieval of soil salinity using hyperspectral data in the region of Inner Mongolia Hetao irrigation district. Spectroscopy and Spectral Analysis 29:1362-1366 DOI 10.3964/j.issn.1000-0593(2009)05-1362-05.

Savitzky A, Golay MJE. 1964. Smoothing and differentiation of data by simplified least squares procedures. Analytical Chemistry 36:1627-1639 DOI 10.1021/ac60214a047.

Schofield RV, Kirkby MJ. 2003. Application of salinization indicators and initial development of potential global soil salinization scenario under climatic change. Global Biogeochemical Cycles 17:1-13 DOI 10.1029/2002GB001935.

Shahid S, Rahman K. 2011. Soil salinity development, classification, assessment and management in irrigated agriculture. Boca Raton: CRC Press.

Stenberg B, Viscarra Rossel RA, Mouazen AM, Wetterlind J. 2010. Chapter five-visible and near infrared spectroscopy in soil science. In: Donald LS, ed. Advances in agronomy. Burlington: Academic Press, 163-215 DOI 10.1016/S0065-2113(10)07005-7.

Tavakkoli E, Fatehi F, Coventry S, Rengasamy P, McDonald GK. 2011. Additive effects of $\mathrm{Na}^{+}$and $\mathrm{Cl}^{-}$ions on barley growth under salinity stress. Journal of Experimental Botany 62:2189-2203 DOI 10.1093/jxb/erq422.

The National Soil Survey Office. 1998. Soils of China. Beijing: China Agriculture Press (in Chinese).

Urdanoz V, Aragüés R. 2011. Pre- and post-irrigation mapping of soil salinity with electromagnetic induction techniques and relationships with drainage water salinity. Soil Science Society of America Journal 75:207-215 DOI 10.2136/sssaj2010.0041.

Vapnik VN. 1995. The nature of statistical learning theory. New York: Springer-Verlag.

Viscarra Rossel RA, Behrens T. 2010. Using data mining to model and interpret soil diffuse reflectance spectra. Geoderma 158:46-54 DOI 10.1016/j.geoderma.2009.12.025.

Viscarra Rossel RA, Taylor HJ, McBratney AB. 2007. Multivariate calibration of hyperspectral $\gamma$-ray energy spectra for proximal soil sensing. European Journal of Soil Science 58:343-353 DOI 10.1111/j.1365-2389.2006.00859.x.

Viscarra Rossel RA, Walvoort DJJ, McBratney AB, Janik LJ, Skjemstad JO. 2006. Visible, near infrared, mid infrared or combined diffuse reflectance spectroscopy for simultaneous assessment of various soil properties. Geoderma 131:59-75 DOI 10.1016/j.geoderma.2005.03.007.

Viscarra Rossel RA, Webster R. 2012. Predicting soil properties from the Australian soil visible-near infrared spectroscopic database. European Journal of Soil Science 63:848-860 DOI 10.1111/j.1365-2389.2012.01495.x.

Volkan Bilgili A, Van Es HM, Akbas F, Durak A, Hively WD. 2010. Visible-near infrared reflectance spectroscopy for assessment of soil properties in a semi-arid area of Turkey. Journal of Arid Environments 74:229-238 DOI 10.1016/j.jaridenv.2009.08.011.

Wang H, Jiang T, John AY, Li Y, Tian T, Wang J. 2018a. Hyperspectral inverse model for soil salt ions based on support vector machine. Transactions of the Chinese Society for Agricultural Machinery 49:263-270 (in Chinese)

DOI 10.6041/j.issn.1000-1298.2018.05.031. 
Wang H, Zhang Z, Arnon K, Chen J, Han W. 2018b. Hyperspectral estimation of desert soil organic matter content based on gray correlation-ridge regression model. Transactions of the Chinese Society of Agricultural Engineering 34:124-131 (in Chinese) DOI 10.11975/j.issn.1002-6819.2018.14.016.

Wang J, Ding J, Abulimiti A, Cai L. 2018c. Quantitative estimation of soil salinity by means of different modeling methods and visible-near infrared (VISNIR) spectroscopy, Ebinur Lake Wetland, Northwest China. PeerJ 6:e4703 DOI 10.7717/peerj.4703.

Wang J, Tiyip T, Ding J, Zhang D, Liu W, Wang F, Tashpolat N. 2017. Desert soil clay content estimation using reflectance spectroscopy preprocessed by fractional derivative. PLOS ONE 12:e184836 DOI 10.1371/journal.pone.0184836.

Wang X, Zhang F, Ding J, Kung H, Latif A, Johnson VC. 2018d. Estimation of soil salt content (SSC) in the Ebinur Lake Wetland National Nature Reserve (ELWNNR), Northwest China, based on a Bootstrap-BP neural network model and optimal spectral indices. Science of The Total Environment 615:918-930 DOI 10.1016/j.scitotenv.2017.10.025.

Weng Y, Gong P, Zhu Z. 2008. Reflectance spectroscopy for the assessment of soil salt content in soils of the Yellow River Delta of China. International Journal of Remote Sensing 29:5511-5531 DOI 10.1080/01431160801930248.

Wold S, Sjöström M, Eriksson L. 2001. PLS-regression: a basic tool of chemometrics. Chemometrics and Intelligent Laboratory Systems 58:109-130 DOI 10.1016/S0169-7439(01)00155-1.

Wu J, Vincent B, Yang J, Bouarfa S, Vidal A. 2008. Remote sensing monitoring of changes in soil salinity: a case study in Inner Mongolia, China. Sensors 8:7035-7049 DOI 10.3390/s8117035.

Xia N, Tiyip T, Kelimu A, Nurmemet I, Ding J, Zhang F, Zhang D. 2017. Influence of fractional differential on correlation coefficient between EC1:5 and reflectance spectra of saline soil. Journal of Spectroscopy 2017:1-11 DOI 10.1155/2017/1236329.

Xiao Z, Li Y, Feng H. 2016a. Hyperspectral models and forcasting of physico-chemical properties for salinized soils in northwest China. Spectroscopy and Spectral Analysis 36(5):1615-1622.

Xiao Z, Li Y, Feng H. 2016b. Modeling soil cation concentration and sodium adsorption ratio using observed diffuse reflectance spectra. Canadian Journal of Soil Science 96:372-385 DOI 10.1139/cjss-2016-0002.

Xu C, Zeng W, Huang J, Wu J, Van Leeuwen W. 2016. Prediction of soil moisture content and soil salt concentration from hyperspectral laboratory and field data. Remote Sensing 8:Article 42 DOI 10.3390/rs8010042.

Yang X, Yu Y. 2017. Estimating soil salinity under various moisture conditions: an experimental study. IEEE Transactions on Geoscience and Remote Sensing 55:2525-2533 DOI 10.1109/TGRS.2016.2646420. 
Yu R, Liu T, Xu Y, Zhu C, Zhang Q, Qu Z, Liu X, Li C. 2010. Analysis of salinization dynamics by remote sensing in Hetao Irrigation District of North China. Agricultural Water Management 97:1952-1960 DOI 10.1016/j.agwat.2010.03.009.

Zhang Z, Wang H, Arnon K, Chen J, Han W. 2018. Inversion of soil moisture content from hyperspectra based on ridge regression. Transactions of the Chinese Society for Agricultural Machinery 49:240-248 (in Chinese)

DOI 10.6041/j.issn.1000-1298.2018.05.028. 